\title{
Integrin-linked kinase (ILK) is required for polarizing the epiblast, cell adhesion, and controlling actin accumulation
}

\author{
Takao Sakai, ${ }_{1}^{1}$ Shaohua Li, ${ }^{2}$ Denitsa Docheva, ${ }^{1}$ Carsten Grashoff, ${ }^{1}$ Keiko Sakai, ${ }^{1}$ Günter Kostka, ${ }^{1}$ \\ Attila Braun, ${ }^{1}$ Alexander Pfeifer, ${ }^{3}$ Peter D. Yurchenco, ${ }^{2}$ and Reinhard Fässler ${ }^{1,4}$ \\ ${ }^{1}$ Max Planck Institute of Biochemistry, Department of Molecular Medicine, 82152 Martinsried, Germany; ${ }^{2}$ Department of \\ Pathology and Medicine, Robert Wood Johnson Medical School, Piscataway, New Jersey 08854, USA; ${ }^{3}$ Department of \\ Pharmacy, Center for Drug Research, University of Munich, 81377 Munich, Germany
}

Integrin-mediated cell-matrix interactions are essential for development, tissue homeostasis, and repair. Upon ligand binding, integrins are recruited into focal adhesions (FAs). Integrin-linked kinase (ILK) is an FA component that interacts with the cytoplasmic domains of integrins, recruits adaptor proteins that link integrins to the actin cytoskeleton, and phosphorylates the serine/threonine kinases PKB/Akt and GSK-3ß. Here we show that mice lacking ILK expression die at the peri-implantation stage because they fail to polarize their epiblast and to cavitate. The impaired epiblast polarization is associated with abnormal F-actin accumulation at sites of integrin attachments to the basement membrane (BM) zone. Likewise, ILK-deficient fibroblasts showed abnormal F-actin aggregates associated with impaired cell spreading and delayed formation of stress fibers and FAs. Finally, ILK-deficient fibroblasts have diminished proliferation rates. However, insulin or PDGF treatment did not impair phosphorylation of PKB/Akt and GSK-3 $\beta$, indicating that the proliferation defect is not due to absent or reduced ILK-mediated phosphorylation of these substrates in vivo. Furthermore, expression of a mutant ILK lacking kinase activity and/or paxillin binding in ILK-deficient fibroblasts can rescue cell spreading, F-actin organization, FA formation, and proliferation. Altogether these data show that mammalian ILK modulates actin rearrangements at integrin-adhesion sites.

[Keywords: Integrin; integrin-linked kinase (ILK); epiblast; knockout]

Received November 19, 2002; revised version accepted February 10, 2003.

Integrins mediate cell-cell and cell-matrix adhesions, which play crucial roles for embryonic development, maintenance, and repair of tissues and organs (Hynes 2002). Integrin-ligand interactions elicit outside-in signals by modulating various intracellular signalling pathways, resulting in cytoskeletal reorganization and changes in gene expression that affect adhesion and migration, proliferation, differentiation, and survival of cells (Giancotti and Ruoslahti 1999; Brakebusch et al. 2002). Intracellular events, on the other hand, can elicit an inside-out signal that modulates the affinity/avidity of integrins (Hynes 2002).

A crucial binding partner of integrin cytoplasmic domains is the integrin-linked kinase (ILK). ILK was identified to interact with the $\beta 1-, \beta 2-$, and $\beta 3$-integrin cytoplasmic tails (Hannigan et al. 1996). ILK is composed of four ankyrin (ANK) repeats, a pleckstrin homology $(\mathrm{PH})$ domain, and a C-terminal Ser/Thr kinase domain. The

${ }^{4}$ Corresponding author.

E-MAIL faessler@biochem.mpg.de; FAX 49-89-8578-2422.

Article and publication are at http://www.genesdev.org/cgi/doi/10.1101/ gad.255603. first ANK domain can bind the LIM-domain-only proteins PINCH1 and 2 (Zhang et al. 2002; Braun et al. 2003), which have been shown to interact with the SH2/ SH3-containing adaptor protein Nck2 (or Grb4; Tu et al. 1998). The kinase domain interacts with the $\beta 1-, \beta 2-$, and $\beta 3$-integrin tails, paxillin, and a new family of actinbinding proteins termed $\alpha$-parvin (also named CH-ILKBP or actopaxin; Nikolopoulos and Turner 2000; Olski et al. 2001; Tu et al. 2001) and $\beta$-parvin (also named affixin; Olski et al. 2001; Yamaji et al. 2001), which can bind $\alpha$ PIX, a guanine nucleotide exchange factor for Rac and Cdc42 (Rosenberger et al. 2003). Although the ILK kinase domain lacks critical consensus sequences of Ser/Thr kinases, several studies showed that ILK has kinase activity. ILK can phosphorylate peptides and standard substrates such as myelin basic protein in vitro (Hannigan et al. 1996; Delcommenne et al. 1998). In line with these findings, overexpression of ILK or insulin treatment results in increased phosphorylation of GSK- $3 \beta$ and PKB/ Akt (Delcommenne et al. 1998). GSK-3 $\beta$ is a negative regulator of Wnt signaling. Wnt signals as well as ILK inactivate GSK-3 $\beta$ by phosphorylation, leading to the stabilization and elevation of $\beta$-catenin levels and trans- 
location into the nucleus, where $\beta$-catenin interacts with Lef-1/Tcf, leading to the activation of gene expression including cyclin D1 and c-myc. The formation of Lef- $1 /$ Tcf- $\beta$-catenin complexes has also been observed in ILK-overexpressing cells (Novak et al. 1998). PKB/Akt is a Ser/Thr kinase implicated in cell proliferation, survival, and insulin signaling. Full activation of PKB/Akt requires phosphorylation on residues Thr 308 and Ser 473. The Thr 308 kinase is called 3-phosphoinositidedependent kinase 1 (PDK1) and is well characterized (Lawlor and Alessi 2001), whereas the PI3-kinase dependent kinase that phosphorylates Ser 473, termed PDK2, is less well characterized. Extensive studies by Dedhar and coworkers suggested that ILK is PDK2 (Persad et al. 2001). Recent observations, however, question whether ILK is a bona fide kinase. Two independent studies show that ILK is part of a multiprotein complex in mammalian cells, in which ILK supports phosphorylation of Ser 473 of PKB/Akt by an indirect mechanism (Lynch et al. 1999; Hill et al. 2002). Furthermore, flies as well as worms expressing an inactive kinase ILK gene are normal, suggesting no role of the kinase activity of ILK in vivo (Zervas et al. 2001; Mackinnon et al. 2002).

Genetic analyses of the ILK ortholog in Drosophila melanogaster and Caenorhabditis elegans and overexpression of ILK in epithelial cells identified ILK as an important mediator of integrin function. The absence of ILK expression in Drosophila leads to a severe defect in integrin-mediated adhesion. Interestingly, both ILK- and PS-integrin-deficient flies exhibit muscle detachment, but the initial alterations leading to this defect are different. In muscle lacking PS integrin, the plasma membrane detaches from the extracellular matrix (ECM) but still anchors actin filaments. In contrast, ILK-deficient muscle correctly localizes integrins and binds ECM but fails to attach actin filaments to the membrane, suggesting that ILK is a structural component that links the cytoskeleton and the plasma membrane at sites of integrin-mediated adhesion (Zervas et al. 2001). In C. elegans, the homolog of mammalian ILK is found in bodywall muscles, where it concentrates together with $\beta$-integrin/PAT-3 at focal adhesion-like muscle-attachment sites (dense bodies). Loss of ILK expression leads to an embryonic lethal phenotype called PAT (paralyzed and arrested elongation at the twofold stage) and resembles the loss-of-function phenotype of $\beta$-integrin/PAT-3 (Mackinnon et al. 2002).

Studies with cultured cell lines suggest that ILK can act as a proto-oncogene, stimulate epithelial-mesenchymal transformation, and modulate cellular differentiation. Overexpression of wild-type ILK in intestinal epithelial cells promotes anchorage-independent growth and tumorigenicity in nude mice (Wu and Dedhar 2001). Several molecular mechanisms have been proposed to be responsible for these effects, including the activation of cyclins and cyclin-dependent kinases (cdk), the reduction of E-cadherin expression, stabilization of $\beta$-catenin, and the formation of Lef- $1 /$ Tcf- $\beta$-catenin complexes $(\mathrm{Wu}$ and Dedhar 2001). Overexpression of ILK in C2C12 myoblasts inhibits the formation of multinucleated myo- tubes. This defect is suggested to be caused by the suppression of myogenic protein expression, including MyoD and myosin heavy chain, and by a failure to inactivate MAP kinase and hence to exit the cell cycle (Huang et al. 2000). Finally, it has been shown that overexpression of ILK can efficiently stimulate fibronectin (FN) assembly, suggesting also a role for ILK in insideout signaling (Wu et al. 1998).

In the present paper, we report the defects of ILK-deficient mice and cells. We show that ILK is important for the polarization of the epiblast, for cell adhesion, and FA formation. The defects are accompanied by abnormal actin reorganization, which can be rescued with a mutant ILK lacking kinase activity. Surprisingly, PKB/Akt and GSK-3 $\beta$ can be efficiently phosphorylated in ILK-deficient cells, supporting the argument that ILK has no essential kinase activity on these substrates in vivo.

\section{Results}

Generation of ILK-deficient and ILK-floxed mice

To generate a targeting construct, we first screened a PAC library representing two times the mouse genome and isolated seven clones. Four clones harbored a pseudogene characterized by a single exon containing several stop codons. The sequence of the pseudogene was localized to Chromosome 13 by computer searches of Ensemble as well as Celera mouse genome databases. The remaining clones coded for the same ILK gene and could be assigned to Chromosome 7, suggesting that the mouse genome harbors one functional ILK gene.

To generate ILK-deficient mice, the targeting construct ILK ${ }^{\text {lacZ }}$ was electroporated into embryonic stem (ES) cells (Fig. 1A). Out of 360 ES cell clones analyzed, seven targeted clones were identified by Southern blot. Two clones were used to produce germ-line chimeric males. Germ-line transmission of the mutated ILK gene was confirmed by Southern blot analysis (Fig. 1B). The targeting construct ILK ${ }^{\mathrm{fl}}$ was electroporated into ES cells to generate $I L K$-null ES cells (Fig. 1A). Out of 180 ES cell clones analyzed, 48 targeted clones were identified by Southern blot analysis. Four of them were transiently transfected with a Cre-recombinase expression plasmid, selected in FIAU, and analyzed for Cre-mediated deletion (Fig. 1C).

Two ES cell clones carrying a single constitutive null allele were electroporated again with the ILK ${ }^{\mathrm{fl}}$ construct. ES cell clones with a recombination event on the wildtype allele were transiently transfected with the Cre expression plasmid to obtain ES cell clones with a homozygous deletion of the ILK gene (Fig. 1C). To determine whether the mutant mRNA was translated, cell lysates of floxed, heterozygous, and homozygous ILK ES cells and NIH3T3 cells were subjected to immunoblotting analysis using two mAbs and one polyclonal antiserum against ILK. The lysate of ES cells with a homozygous deletion of both ILK genes showed no ILK signal with either antibody, whereas floxed and heterozygous ES cells and NIH3T3 cells showed an ILK protein with an 
Sakai et al.

Figure 1. Targeting strategy and DNA and protein analysis of mutant $I L K$ alleles. (A) Partial map of the wild-type ILK allele, $I L K^{1 a c Z}$, ILK-floxed allele $\left(I L K^{f 1}\right)$, and the $I L K$-null allele after Cre-mediated recombination. Exons and lox $P$ sequences are indicated as rectangles and triangles, respectively. The DNA fragment length obtained after Southern blotting and the external (probe 1) and internal (probe 2) probes are indicated. Restriction sites are: $\mathrm{B}, \mathrm{BamHI}$; H3, HindIII. (B) Southern blot of ILK ${ }^{\text {lacZ }}$ tail DNA wild-type $(+/+)$ and heterozygous $(+\mid-)$ tail DNA following digestion with BamHI and hybridization with probe 1 . The sizes of the wild-type $(20 \mathrm{~kb})$ and targeted $(9.5 \mathrm{~kb})$ bands are indicated. $(C)$ Southern blot of floxed ES cell DNA before and after transient expression of Cre, following digestion of $\mathrm{BamHI}$ and hybridization with probe $2 .+/+$, wild type; $\mathrm{fl} /+$, , heterozygous for the ILK-floxed gene; +/-, heterozygous for the ILK-null gene; -/-, homozygous for the ILK-null gene. The sizes of the wild-type $(20 \mathrm{~kb})$, ILK-floxed $(10.5 \mathrm{~kb})$, and $I L K$-null $(9.5 \mathrm{~kb})$ bands are indicated. $(D)$ Western blot analysis of ILK protein expression in NIH3T3, and ES cells that are wild-type $(+/+)$, heterozygous for the ILK-floxed gene $(\mathrm{fl} /+)$, heterozygous for the ILK-null gene $(+\mid-)$, and homozygous for the ILK-null gene (-/-). The position of a molecular mass marker $(\mathrm{kDa})$ is indicated.
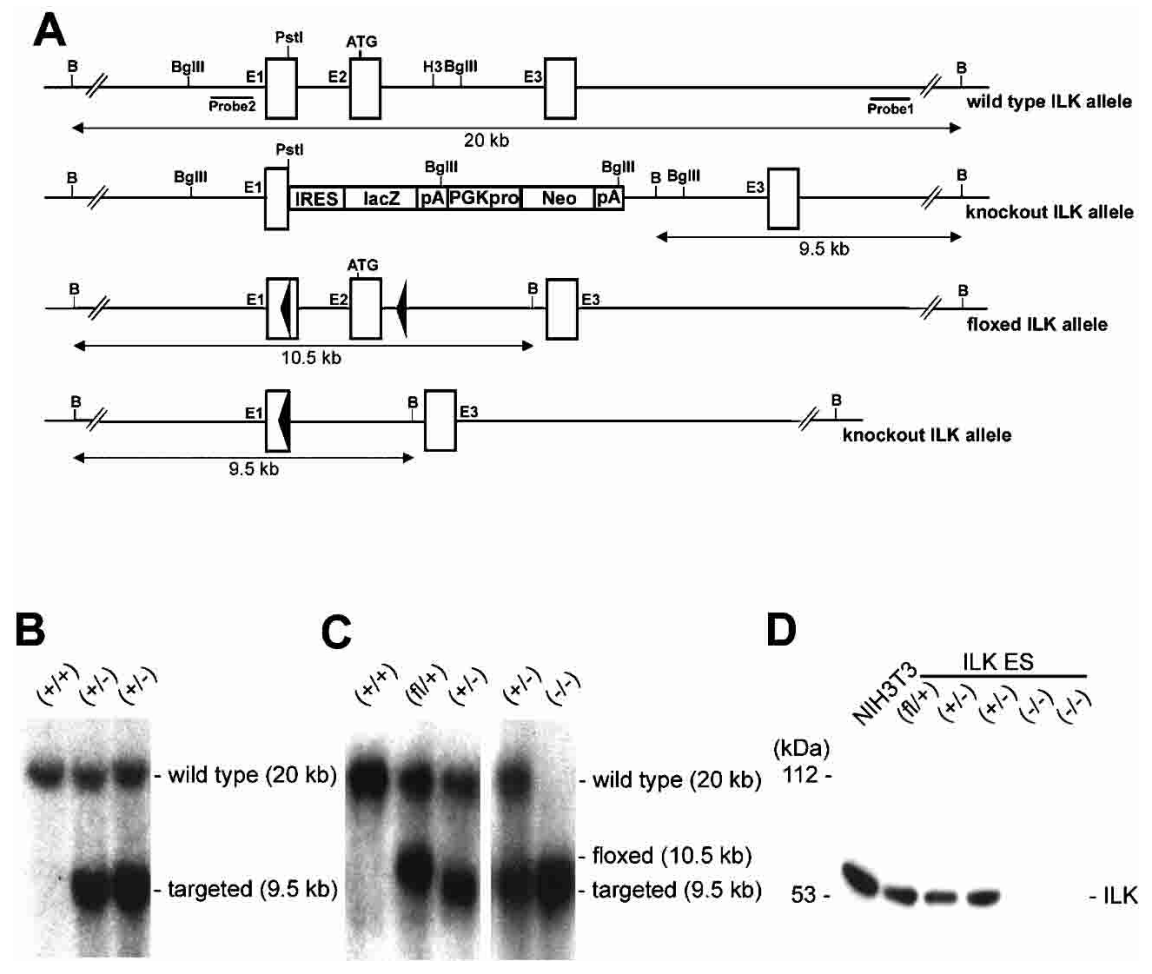

apparent molecular mass of 50-53 kD (Fig. 1D). These data indicate that the Cre-mediated deletion of exon 1 and exon 2 results in loss of ILK protein expression.

To determine $I L K$ expression during development, heterozygous $I L K^{\text {lac } Z}$ embryos were collected at embryonic day 8.5 (E8.5) or E10.5 and subjected to whole mount lacZ staining. The $I L K^{\text {lac } Z}$ allele was highly expressed in the heart and somites and weakly throughout the remaining embryos (data not shown). Tissue sections derived from adult mice revealed strong lacZ staining in all tissues in almost all cells. Very robust signals were observed in chondrocytes, lung epithelial cells, skeletal and cardiac muscle, pyramidal cells of the cortex, Purkinje cells, kidney epithelial cells, and cells of the crypts of the small and large intestine (data not shown).

\section{ILK-null mice die shortly after implantation}

Mice heterozygous for the $I L K^{1 a c Z}$ mutation appeared normal and did not display any overt anatomical or behavioral abnormalities. To obtain mice homozygous for $I L K^{l a c Z}$, heterozygous mice were intercrossed. Among 389 viable offspring, $64 \%$ were identified as heterozygotes and $36 \%$ as wild type. No homozygous mutant mice were among the progeny, indicating that they die during embryonic development.

To determine whether ILK is crucial for preimplanta- tion development, E3.5 blastocysts were isolated from the uterus of heterozygous females mated with heterozygous males. A total of 33 blastocysts were isolated and were phenotypically alike. To test whether ILK-deficient blastocysts were among them, they were immunostained with anti-ILK antibodies. Among the 33 blastocysts, 6 blastocysts lacked ILK expression (Fig. 2A). The remaining embryos showed a strong ILK signal in the trophectoderm as well as inner cell mass (ICM; Fig. 2A).

To determine the time of embryonic lethality, heterozygous mice were intercrossed and decidua swellings were collected at E5.5, E8.5, and E9.5 and sectioned. Out of 23 E6 implantation chambers, 19 had formed egg cylinders and 4 were completely resorbed (Fig. 2B). ILK-deficient blastocysts formed normally, and their contact with the uterus wall induced a decidua reaction leading to the formation of an implantation chamber. Around $25 \%$ of the implantation chambers were empty and hence lacked tissue to confirm the absence of ILK expression. Therefore, we assigned the empty implantation chambers to presumptive ILK-null embryos. The analysis of 124 E8.5 and E9.5 implantation chambers further supported peri-implantation lethality of $I L K$-null embryos. In 18 neither embryos nor cells could be found. PCR genotyping of DNA derived from embryos from the remaining sites confirmed that normal embryos were either wild type or heterozygous for the ILK ${ }^{l a c Z}$ mutation. 


\section{A}
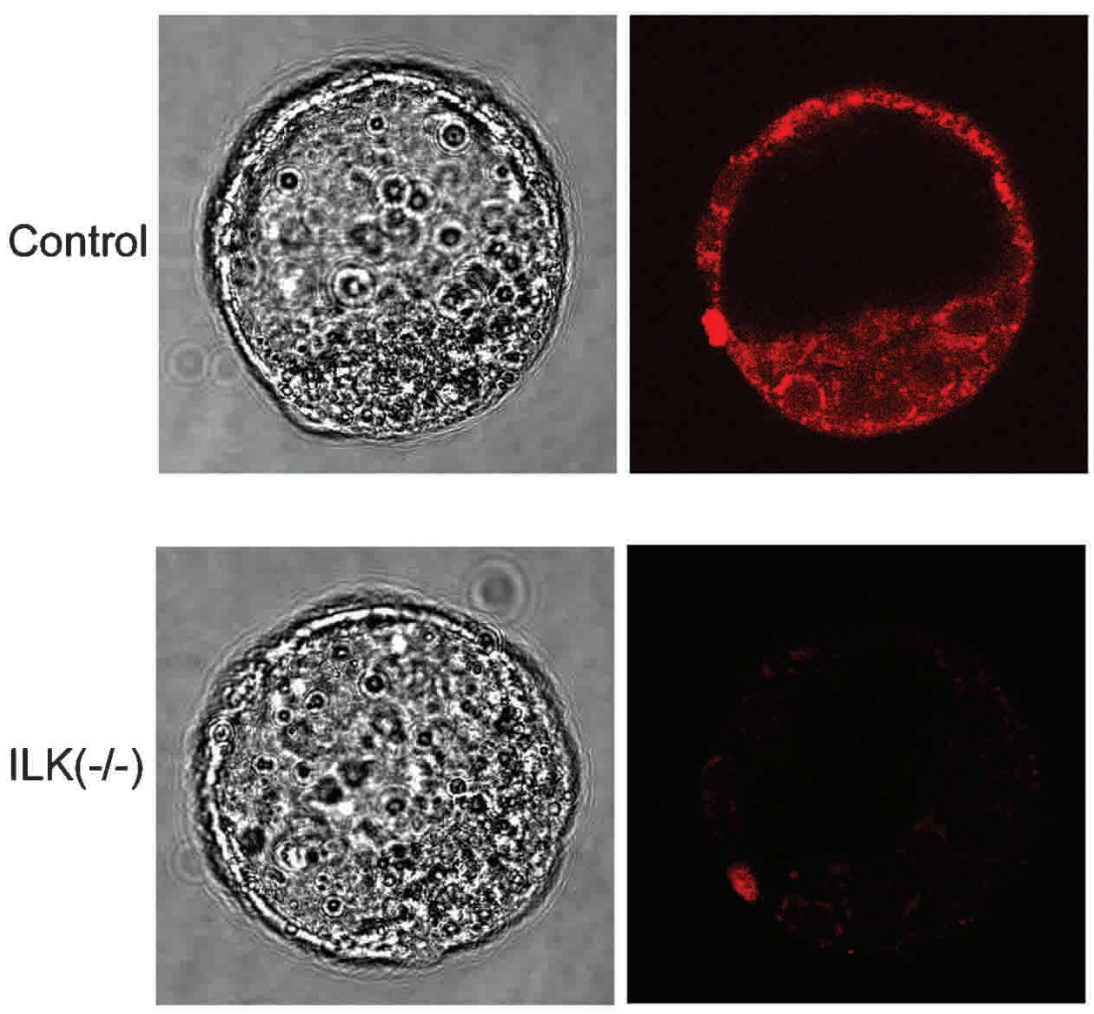
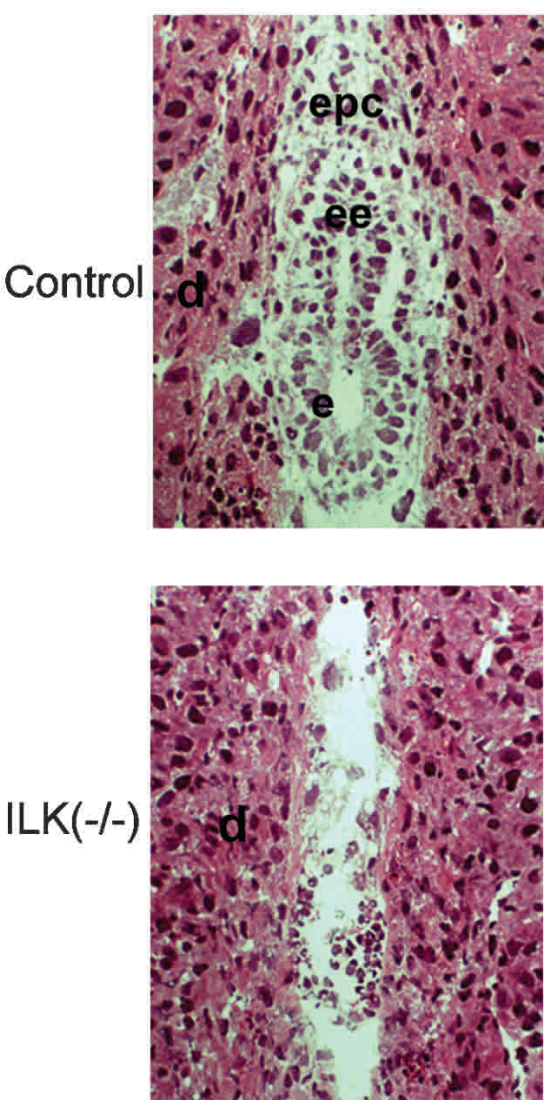

Figure 2. Embryos from ILK ${ }^{\text {lacZ }}$ heterozygous intercrosses. $(A)$ Blastocysts were fixed and immunostained for ILK and photographed in solution. ILK-null blastocysts are indistinguishable from control blastocysts. $(B)$ Hematoxylin and eosin-stained tissue sections of E5.5 decidua chambers from heterozygous crosses. A control embryo and a presumptive ILK-deficient $(-/-)$ embryo are shown. The implantation chamber of the ILK-deficient embryo contained blood cells but no cells from the embryo proper. d, decidua; epc, ectoplacental cone; ee, extraembryonic ectoderm; e, ectoderm.

\section{ILK-null embryoid bodies fail to form a mature epiblast}

During implantation, ICM cells form an outer layer of endoderm, which deposits a BM. Subsequently, the remaining ICM cells differentiate into the columnar epiblast epithelium, while cells residing deeper within the ICM undergo apoptosis and thereby form the proamniotic cavity. Because cell differentiation in embryoid bodies (EBs) closely reflects that of the ICM during the periimplantation period (Coucouvanis and Martin 1995), we generated ILK-null EBs to delineate the reason for the peri-implantation lethality caused by loss of ILK expression.

Wild-type and $I L K$-null ES cells were cultured in suspension as EBs for 6-9 d. Light microscopy of 6-7-d EB cultures (Figs. 3,4 ) revealed that almost all wild-type and most ILK-null EBs showed endodermal differentiation characterized by a distinct outer layer of often domed, vacuolated, and ciliated cells. Wild-type EBs formed a polarized epiblast layer and had well-formed central cavities that occupied most of the interior space (Figs. $3 \mathrm{~A}, 4 \mathrm{~A})$. In contrast to normal EBs, the ILK-null EBs did not possess well-formed epiblasts, that is, a pseudostratified columnar arrangement of cells extending from the BM to the edge of the cavity (Fig. 3B). Instead, the cells lining the BM were polygonal in their morphology and often indistinguishable from ICM (Fig. 4B,D). Only a small fraction of the ILK-null EBs had prominent cavities that were seen by phase microscopy. These were incomplete in that they were usually eccentric in location (Fig. 4B). Examination of $I L K^{-/-}$EBs in phalloidinstained frozen sections (Fig. 3I-L) and Epon thick sections (Fig. 4B, arrowhead) revealed additional smaller slit-like spaces, often the size of only several cells, that had prominent F-actin at their edges (Fig. $3 \mathrm{~L}, \mathrm{~L}^{\prime}, \mathrm{L}^{\prime \prime}$ ). These were found in many $I L K$-null EBs that had formed a BM.

Wild-type and $I L K$-null EBs were enumerated by phase microscopy; $79 \%$ and $63 \%$ of wild-type EBs $(\mathrm{n}=120)$ contained BMs and well-formed cavities, respectively, whereas $26 \%$ and $4.2 \%$ of ILK-null EBs $(\mathrm{n}=262)$ con- 


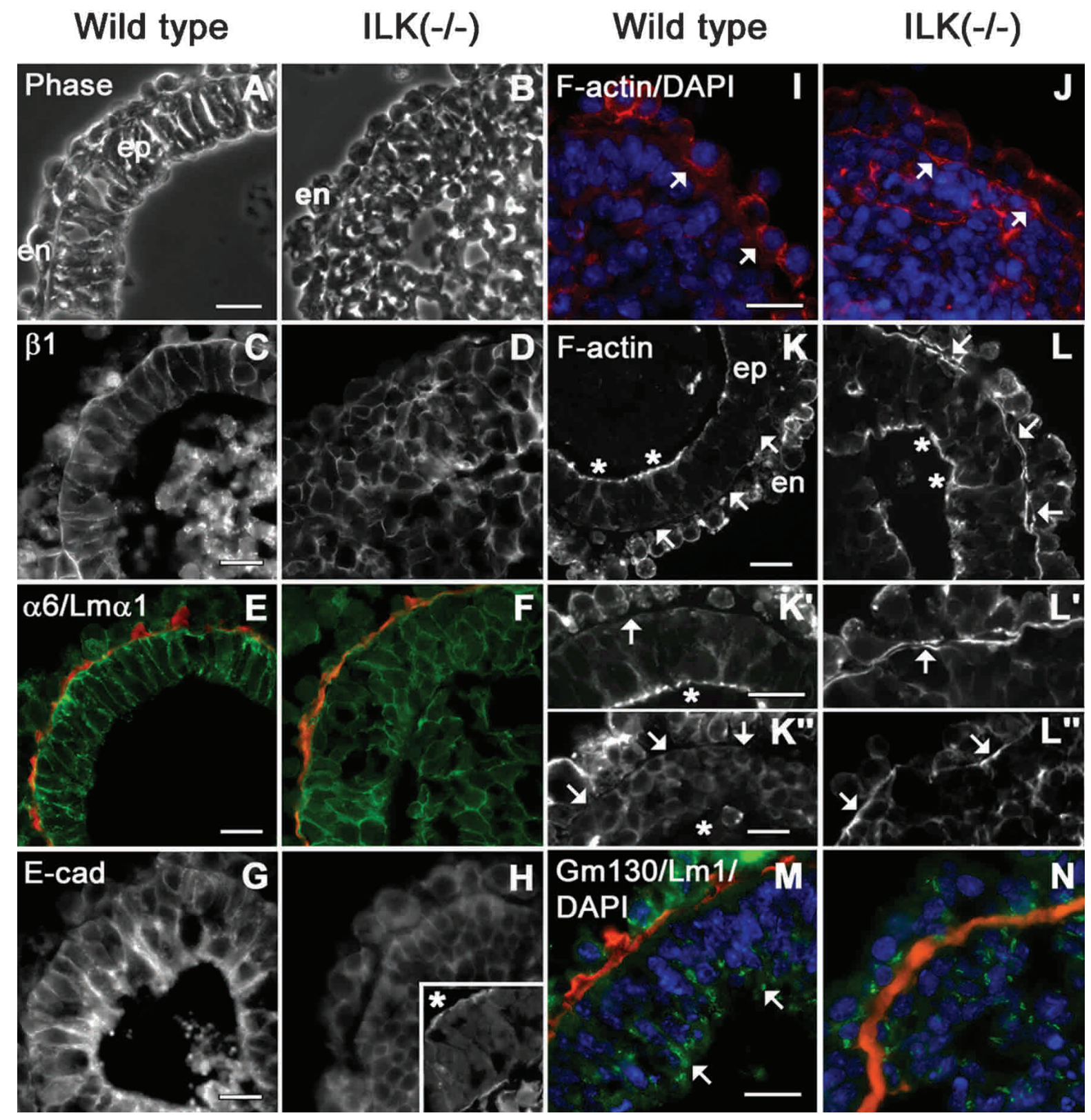

Figure 3. Localization of laminins, integrins, E-cadherin, $\beta$-catenin, and F-actin in EBs. Wild-type and $I L K$-null EBs were cultured in suspension for $7 \mathrm{~d}$ and examined by phase-contrast $(A, B)$ and fluorescence microscopy prepared for immunostaining of $\beta 1$ - and $\alpha 6$-integrin subunits, laminin $\alpha 1$, E-cadherin, F-actin, and GM130 $(C-N)$. (A) Wild-type EBs consisted of an outer layer of endoderm (en), a BM, and pseudostratified columnar epiblasts (ep) facing a sharply demarcated central cavity. (B) The ICM of $I L K$-null EBs failed to differentiate into epiblasts. $(C-F) \beta 1$ - and $\alpha 6$-integrins were localized at the plasma membrane of epiblast (wild-type) and ICM cells (ILK-null), and to a lesser degree, of the endodermal cells. $(E, F)$ Intense integrins were also seen in the BM zone where laminin 1 (laminin $\alpha 1$ epitope in red) and other BM components (data not shown) were present. $(G, H)$ E-Cadherin was distributed in cell peripheries both in wild-type and $I L K$-null epiblast cells. ( $H$, inset) The apical distribution of E-cadherin facing the slit-like cavity (indicated by an asterisk) at higher magnification. (I) A weak F-actin signal (F-actin in red; DAPI in blue) was present evenly distributed beneath the plasma membrane of ICM cells adjacent to the BM. The arrow indicates the location of the BM. (J) ICM cells adjacent to the BM in ILK-null EBs show strong F-actin staining prior to polarization. The arrow indicates F-actin beneath the plasma membrane of ICM cells adjacent to the BM. $(K)$ F-Actin was strongly present on an apical belt within epiblast cells that faced the cavities $\left(K, K^{\prime}\right.$; asterisks) but not in the BM zone $\left(K, K^{\prime}, K^{\prime \prime}\right.$; arrows). $(L) I L K$-null EBs showed strong F-actin staining at the side facing the $\mathrm{BM}\left(L, L^{\prime}, L^{\prime \prime}\right.$; arrows), although $I L K$-null EBs with small cavities or slits could gain a columnar shape and F-actin at their apices $(L ;$ asterisks). ( $M, N)$ GM130 (GM130 epitope in green; laminin 1 epitope in red; DAPI in blue) in wild-type EBs was observed in epiblast cells adjacent to the cavity edge but not ILK-null EBs. $\alpha 6$, $\alpha 6$-integrin subunit; $\beta 1, \beta 1$-integrin subunit; E-cad, E-cadherin; Lm1, laminin 1; Lm $\alpha 1$, laminin $\alpha 1$. Bars, $20 \mu \mathrm{m}$. 

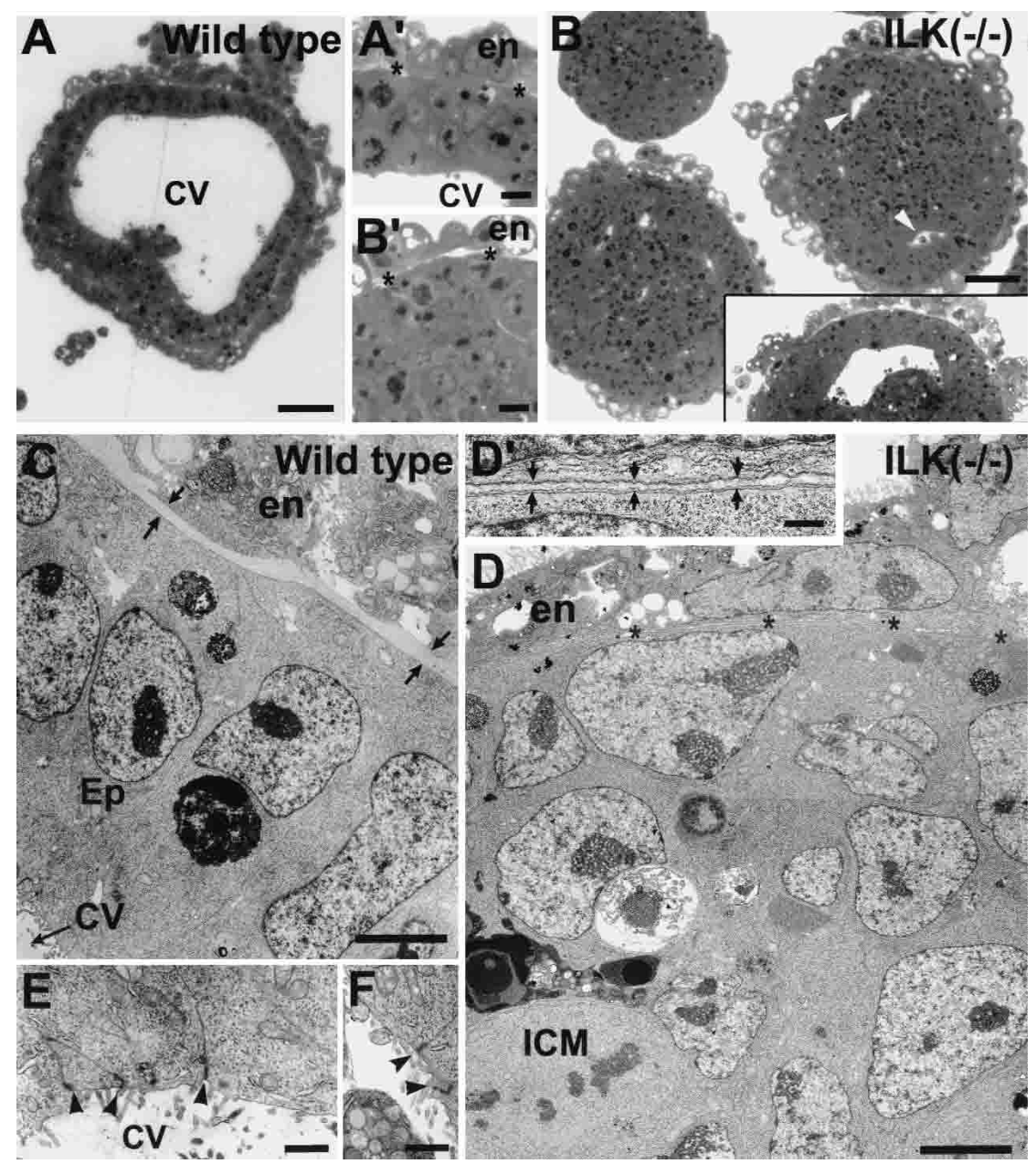

Figure 4. Ultrastructural analysis of EBs. Epon-embedded sections of wild-type $(A, C, E)$ and $I L K$-null $\left(I L K^{-1-} ; B, D, F\right)$ EBs were cultured for $7 \mathrm{~d}$ and then examined by light $(A, B)$ and electron microscopy $(C-$ $F$ ). Panels $C$ and $D$ were prepared from composite overlapping micrographs $E$ and F. $\left(A, A^{\prime}\right)$ The wild-type EBs possessed large cavities, radially oriented elongated epiblast (Ep) cells, often extending from the $\mathrm{BM}$ to the cavity $(\mathrm{CV}) .\left(B^{\prime}, D, D^{\prime}\right)$ The $I L K$ null EBs possessed an outer endoderm layer (en) and thin BM (asterisks and zone between arrows), and ICM cells, which were polygonal in shape. Junctional complexes (arrowheads in $E, F$ ) were noted predominantly in wild-type cells adjacent to cavities $(E)$. They were also noted in ICM cells adjacent to the incomplete cavities that formed in a small fraction of $I L K$-null EBs $(F)$. Bars: $A, B, 50 \mu \mathrm{m} ; A^{\prime}, B^{\prime}, 10 \mu \mathrm{m}$; $C, D, 5 \mu \mathrm{m} ; D^{\prime}, 1 \mu \mathrm{m} ; E, F, 0.5 \mu \mathrm{m}$. tained cavities. No ILK-null EBs evaluated (n = 215) exhibited full epiblast differentiation (as judged by microscopic appearance), whereas $50 \%$ of wild-type EBs ( $\mathrm{n}=250)$ contained epiblast. To test whether the defect is caused by delayed differentiation, normal and ILK-null EBs were cultured for as long as $9 \mathrm{~d}$ (data not shown). Although the number of wild-type EBs containing epiblast further increased, ILK-null EBs still failed to differentiate and instead were found to degenerate.

Next, normal and $I L K$-null EBs were examined for the expression of $\alpha 6$ - and $\beta 1$-integrin subunits, BM components, E-cadherin, $\beta$-catenin, F-actin, and GM130 (a cisGolgi membrane protein). Laminin, collagen IV, nidogen, and perlecan were distributed as continuous linear deposits underlying the endodermal layer in wild-type as well as in $I L K$-null EBs (Fig. 3E,F,M,N; data not shown). The $\beta 1$ - and $\alpha 6$-integrin subunits were distributed at cell peripheries and were most prominent in the BM zone (Fig. 3C-F). E-Cadherin and $\beta$-catenin were present on the apical site of epiblast cells facing the cavity (Fig. 3G; data not shown). A similar distribution of E-cadherin and $\beta$-catenin was also observed in ILK-null EBs that developed slit-like cavities (Fig. $3 \mathrm{H}$; data not shown). A striking difference was evident in F-actin deposition between wild-type and $I L K$-null EBs. Wild-type EBs showed weak
F-actin staining in ICM cells adjacent to the forming BM prior to polarization of the epiblast (Fig. 3I). In the polarized epiblast of control EBs, F-actin was exclusively present on an apical belt within epiblast cells that faced the cavities (Fig. 3K, $\mathrm{K}^{\prime}, \mathrm{K}^{\prime \prime}$ ). In contrast, ILK-null EBs showed strong F-actin staining in polygonal, nonpolarized cells of the ICM at the side facing the BM (Fig. 3J). Moreover, although ICM cells adjacent to the BM of ILK-null EBs with small cavities or slits could gain a columnar shape and F-actin at their apices, they had still strong F-actin deposits at the $B M$ zone (Fig. $\left.3 \mathrm{~L}_{,} \mathrm{L}^{\prime}, \mathrm{L}^{\prime \prime}\right)$. This impaired polarization of columnar cells in ILK-null EBs was further apparent from GM130 staining that visualizes the cis-Golgi distribution. In wild-type EBs, cis-Golgi was observed in developing epiblast cells in a polarized fashion adjacent to the cavity edge (Fig. 3M). This polarized pattern was not appreciated in ILK-null EBs with small cavities or slits (Fig. 3N). The ILK-null EBs had not differentiated further by $9 \mathrm{~d}$ of culturing, with many undergoing degeneration (data not shown).

Examination of methylene blue-stained Epon-embedded thick sections showed ultrastructural differences between wild-type and ILK-null EBs (Fig. 4). The BMs were located between the endoderm and the outer ICM layer

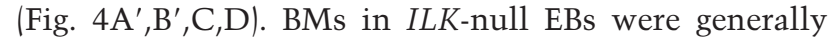


thinner (typically $0.1-0.5 \mu \mathrm{m}$ compared with $0.5-2 \mu \mathrm{m}$; Fig. 4D') than in wild-type EBs (Fig. 4C). The cells underlying the BMs in ILK-null EBs were mostly polygonal, although occasional groups of cells were noted to be elongated but without radial orientation. When present, the small cavities were eccentrically located two or more cell layers beneath the BM. The elongated epiblast cells of the wild-type EBs possessed junctional complexes between cells in the most apical portion facing the cavity (Fig. 4E). These presented as darkly staining double track structures surrounded by filamentous or amorphous darkly staining material. These were tentatively identified as adherens junctions based on their morphology, the strong presence of F-actin and E-cadherin in the apices (Fig. 3K), and the lack of detectable tight junction protein ZO-1 and low levels of pan-keratin intermediate filament staining by immunofluorescence /data not shown). Junctional complexes were found in the small fraction of $I L K$-null EBs containing abortive cavities, that is, in some of the cells in those regions immediately adjacent to the edge of cavities (Fig. 4F).

\section{Cellular differentiation in the absence of ILK}

Because $I L K$-null EBs lacked differentiation of mature epiblast, we asked whether the loss of ILK expression also inhibited differentiation of other cell types including neurogenic, cardiogenic, myogenic, and endothelial cells. To test this, 600 wild-type or ILK-null ES cells were first aggregated in hanging drops for $3 \mathrm{~d}$ and then cultured on gelatin-coated glass coverslips for up to $21 \mathrm{~d}$ $(3+21)$. Wild-type and ILK-deficient EBs showed differentiation of rhythmically contracting cardiomyocytes, neurons, and endothelial cells (Fig. 5; data not shown). E-cadherin staining was strong in many areas of wildtype EBs and showed well-developed epithelial sheets. ILK-deficient EBs also developed epithelial sheets with linear surface expression of E-cadherin, but the sizes of their areas were smaller and they occurred less frequently (Fig. 5A,B; data not shown). Endothelial cell differentiation was monitored by PECAM staining. PECAM-positive cells were observed at $\sim 3+7 \mathrm{~d}$ both in wild-type and ILK-null EBs (data not shown). In wildtype EBs, the PECAM-positive cell clusters began to form branches and at $3+14 \mathrm{~d}$ increased their diameter and had extensively branched. In ILK-null EBs, a similar number of PECAM-positive cell clusters was visible at $3+7 \mathrm{~d}$ but significantly fewer vessel-like branches at $3+14$ d (Fig. 5C,D). Immunostaining for sarcomeric myosin heavy chain (MF-20) revealed the metameric structure of sarcomeres in cardiac muscle cells of wildtype EBs as well as of ILK-deficient EBs (Fig. 5E,F). Immunostaining for neurofilaments identified similar numbers of neuronal cells in wild-type as well as $I L K$ null EBs. A few mutant neurons had long axons; most had short or no axonal extension (Fig. 5G,H).

\section{Integrin expression and adhesion of ILK-deficient cells}

To establish fibroblast-like cells, we generated several immortalized and clonal fibroblastoid cell lines from a kidney of a 4-week-old male ILK ${ }^{\mathrm{fl} / \mathrm{fl}}$ mouse. Subsequently, two clonal lines (5 and 9) were treated with a cre transducing adenovirus to delete the floxed ILK genes. Both cretreated clones showed deletion of both ILK alleles by Southern (data not shown) and lacked ILK expression by Western and immunostaining (Fig. 6; data not shown).

Cell surface expression of integrin subunits in $\mathrm{ILK}^{\mathrm{fl} / \mathrm{fl}}$ (control cells) and ILK-deficient cells was analyzed by FACS. Expression of $\alpha$ subunits $(\alpha 5-, \alpha 6-$, and $\alpha \mathrm{V}$-integrins) and $\beta$ subunits ( $\beta 1$ - and $\beta 3$-integrins) was not significantly altered (data not shown).

Cell adhesion studies showed a dose-dependent response of control cells to vitronectin, fibronectin, and laminin-1 (Fig. 6A). ILK-deficient cells adhered in a dosedependent manner but significantly less to laminin, vitronectin, and fibronectin (Fig. 6A). Control cells spread well on fibronectin and formed arrow-shaped FAs containing paxillin, vinculin, $\alpha$-actinin, and $\beta 1$-integrin $4 \mathrm{~h}$ after plating in serum-free medium. Phalloidin staining revealed the presence of F-actin projecting into FAs (Fig. 6B). ILK-null cells spread significantly less on fibronectin. More than $70 \%$ of the cells were still round $4 \mathrm{~h}$ after plating. The remaining 30\% began to spread but lacked the formation of FAs and typical stress fibers and instead showed clump-like F-actin aggregates, always associated with the plasma membrane (Fig. 6B). When cells were plated for $16 \mathrm{~h}$ on fibronectin, they still exhibited less cell spreading but formed FAs, which contained paxillin, $\alpha$-actinin, vinculin, and $\beta 1$-integrins, and F-actin stress fibers (Fig. 6C), indicating that the kinetics of FA and stress fiber formation is delayed in the absence of ILK expression.

\section{ILK-deficient cells have a diminished proliferation rate but phosphorylate PKB/Akt at Ser 473 and GSK-3ß at Ser 9}

Overexpression of ILK can induce the expression of cyclin D1. Cells with a floxed ILK gene expressed high levels of cyclin D1 and D2 (Fig. 7A), whereas ILK-null cells showed significantly decreased cyclin D2 levels (Fig. 7A). The levels of cyclin D1 were slightly affected at most, and the levels of cyclin A were not changed. In line with the altered levels of cyclin D2, ILK-deficient cells had a significantly diminished proliferation rate by BrdU incorporation (Fig. 7B) and an increased number of cells in the G1 phase of the cell cycle as judged by FACS analysis of propidium iodide-stained cells [ILK-floxed cells, $16.3 \% \pm 4.1 \%$ (3 experiments each with 20,000 cells analyzed); ILK-deficient cells, $25.7 \% \pm 3.9 \%$ (3 experiments each with 20,000 cells analyzed)].

It has been suggested that ILK promotes adhesion-independent cyclin D expression at least in part through phosphorylation of GSK-3 $\beta$ (Ser 9) and PKB/Akt (Ser 473). To directly test whether ILK is required for the phosphorylation of GSK and Ser 473 of PKB we treated quiescent, serum-starved cells of clone 5 and clone 9 with insulin (100 nM) or PDGF (100 ng/mL), respectively, which are known to activate $\mathrm{Pi}(3)$ kinase, which in turn activates ILK. Floxed ILK cells responded to insulin treatment with a rapid and sustainable phosphorylation 

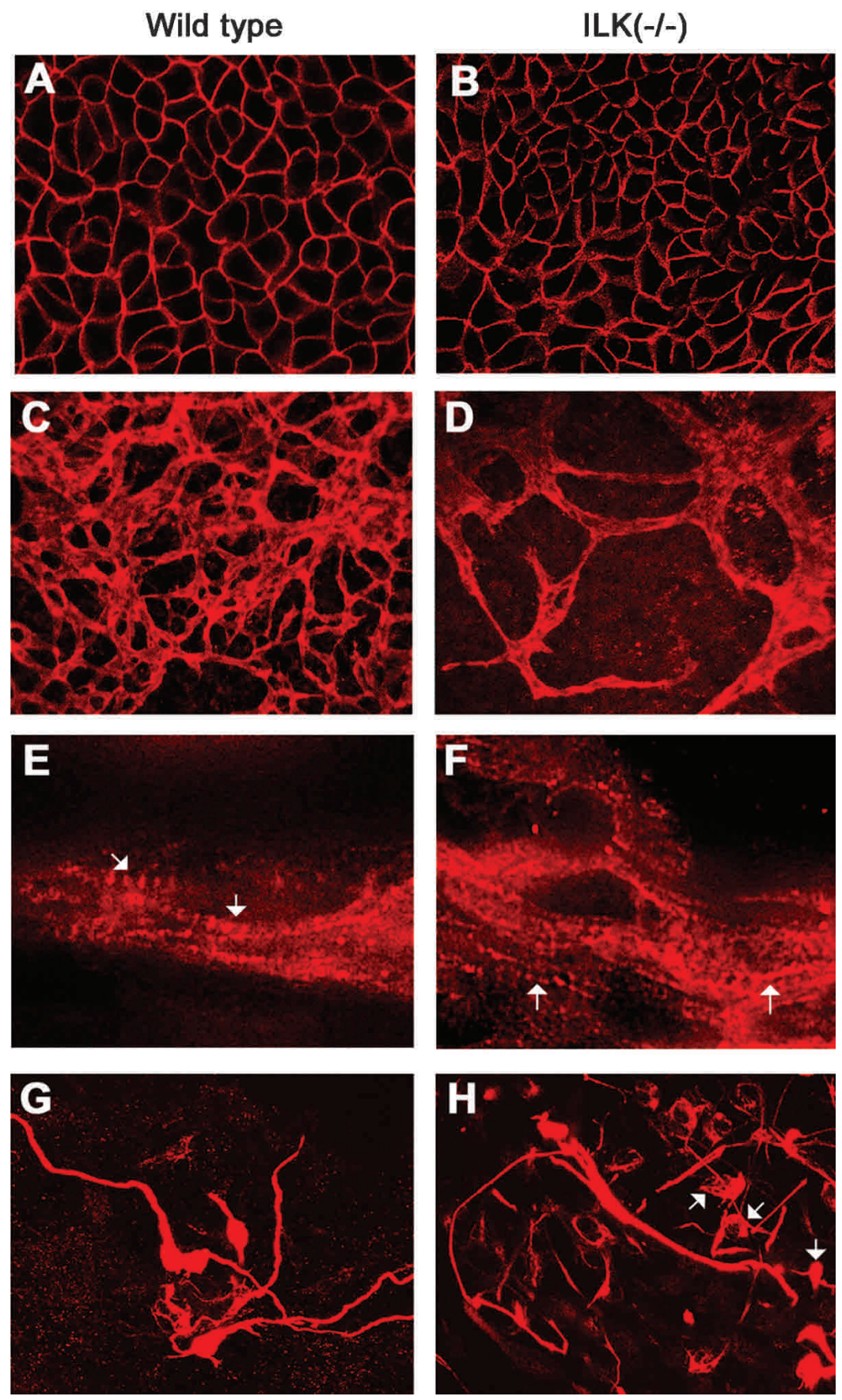

Figure 5. Differentiation of different cell types in wild-type and $I L K$-null EBs. Wild-type or ILKdeficient EBs were cultured for $3 \mathrm{~d}$ in suspension and for $14 \mathrm{~d}$ on a gelatin-coated lab-Tek chamber. The EBs were fixed, immunostained, and analyzed using confocal microscopy. $(A, B)$ Areas of epithelial cells immunostained for E-cadherin expression. Note the fine linear staining on the cell surface in control as well as ILK-null cells. $(C, D)$ Endothelial cells immunostained with anti-PECAM antibodies. In control EBs, endothelial cells organized a vascular-like network. Endothelial cells differentiated in ILK-null EBs but failed to arrange an elaborate network. $(E, F)$ Cardiac muscle cells immunostained with sarcomeric myosin heavy chain. Both control cells and $I L K$-null cells developed sarcomeres (arrow). $(G, H)$ Neuronal cells immunostained for neurofilament expression. Control EBs contained many neuronal cells with long axons, whereas $I L K$-null EBs contained only a few neurons with long axons; most had no or short axonal extension (arrow). of Thr 308 and Ser 473 of PKB/Akt (Fig. 7C). Surprisingly, ILK-deficient cells showed a strong and lasting phosphorylation of Thr 308 and Ser 473 (Fig. 7C) that was indistinguishable from the control cells.

Treatment of floxed control cells with PDGF for 15 min led to a quick and robust phosphorylation of Thr 308 and Ser 473 of PKB/Akt, which was similar in ILK-null cells. Although the phosphorylation of Thr 308 was down-regulated 45 min after PDGF treatment to a similar extent both in control and ILK-null cells, the downregulation of Ser 473 phosphorylation was more pronounced in ILK-null cells (Fig. 7C).
Insulin and PDGF treatment induced low but significant phosphorylation of GSK-3 $\beta$ both in control and ILKnull cells (Fig. 7C). 3T3 cells were used to control the treatment. They respond to PDGF with strong and sustainable phosphorylation of PKB/Akt and GSK-3 $\beta$ (Fig. 7C).

Expression of a mutant ILK cDNA lacking kinase activity in ILK-deficient cells

To test whether the kinase activity is essential for cell spreading, F-actin organization, and stress fiber formation, we generated recombinant retroviruses carrying ei- 
Sakai et al.

A
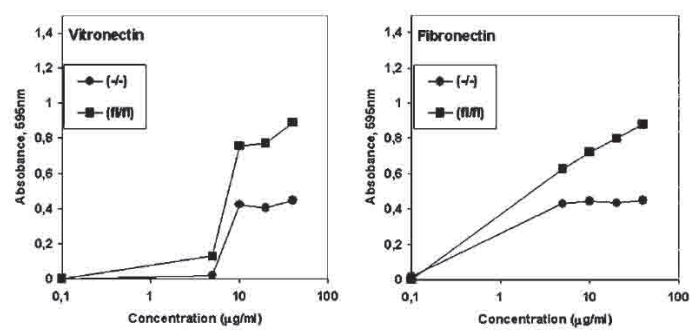

B
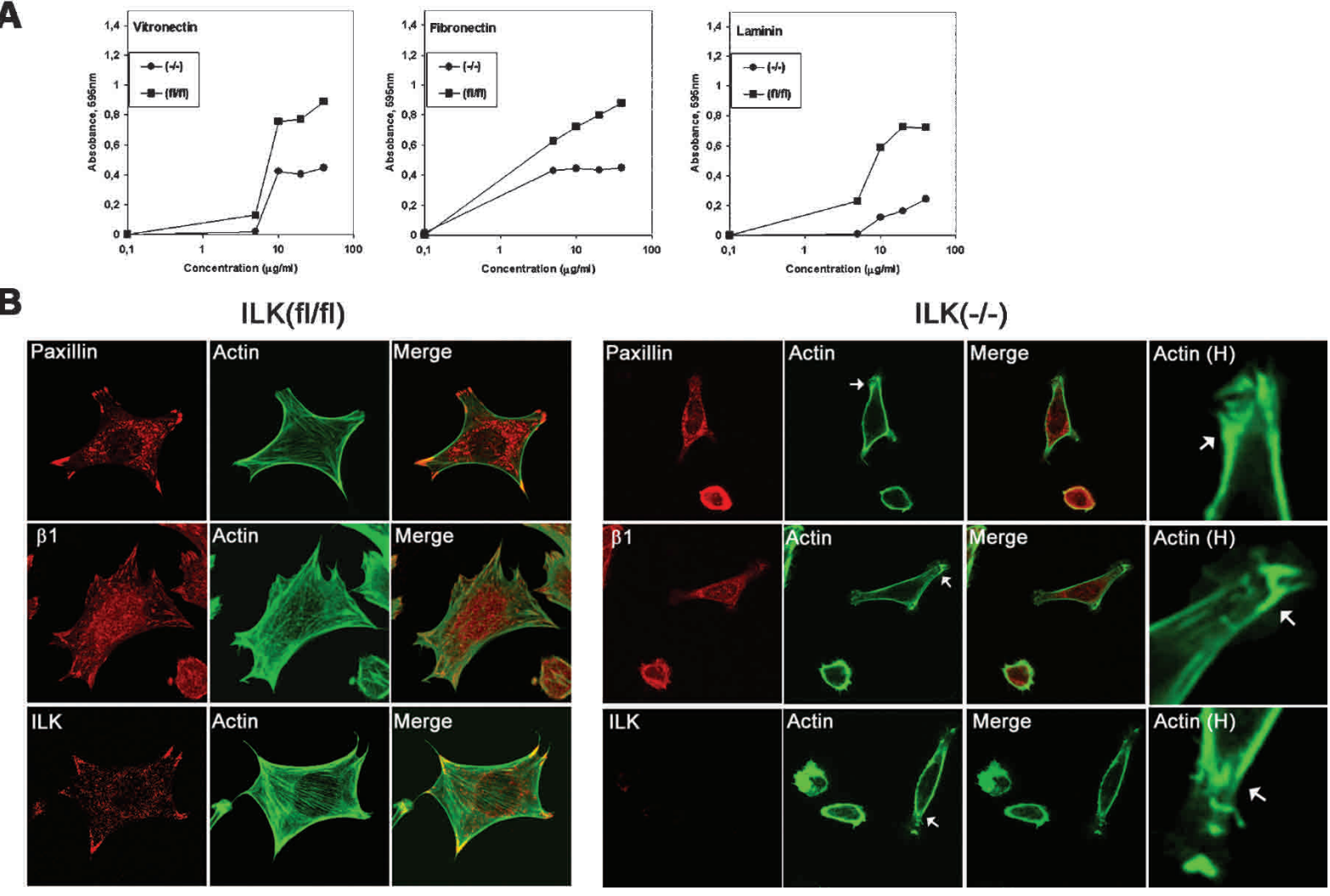

C
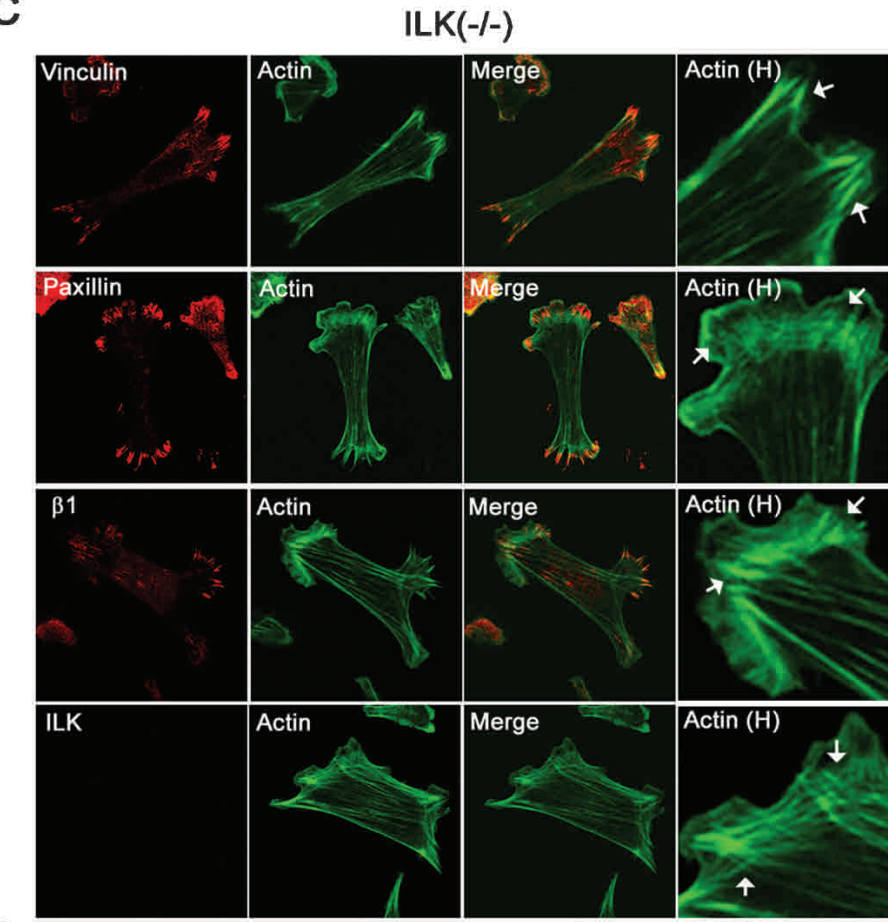

Actin $(\mathrm{H})$
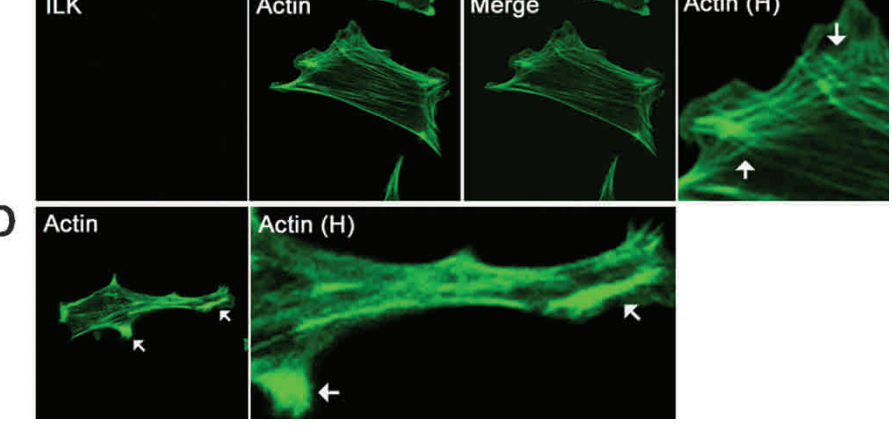

Figure 6. Effect of ILK deletion on adhesion of fibroblasts. (A) Cell adhesion of ILK-floxed (fl/fl) and ILKdeficient $(-/-)$ cells on vitronectin, fibronectin, and laminin-1. Attachment activity was quantified by spectrophotometric analysis at $\mathrm{OD}=595 \mathrm{~nm}$ after staining of adherent cells with crystal violet. (B) Double immunostaining of ILK-floxed (fl/fl) and ILK-deficient (-/-) cells for paxillin/F-actin, $\beta 1$-integrin/F-actin, and ILK/ $\mathrm{F}$-actin $4 \mathrm{~h}$ after adhesion to fibronectin. Note the reduced spreading and the lack of FA formation. Panels labeled Actin $\mathrm{H}$ show F-actin localized to subcortical areas where it formed large aggregates (arrows). (C) Double immunostaining of ILK-deficient $(-/-)$ cells with vinculin/F-actin, paxillin/F-actin, $\beta 1$-integrin/ F-actin, and ILK/F-actin $16 \mathrm{~h}$ after adhesion to fibronectin. ILK-deficient cells were less spread but formed stress fibers and FAs. Aggregates of actin were still present. Panels labeled Actin $\mathrm{H}$ are higher-magnification views showing the increase of F-actin at focal adhesion (arrows). (D) F-Actin aggregates in subcortical areas (arrows; higher-magnification view is shown in panels labeled Actin $\mathrm{H}$ ). 
A

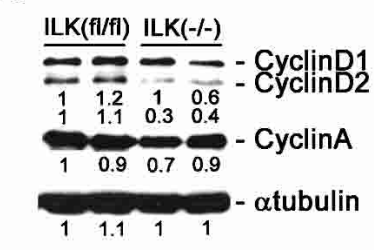

B

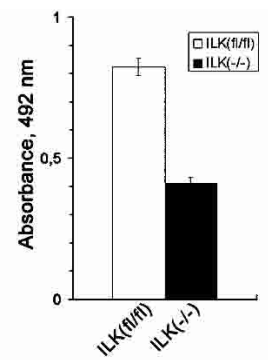

C
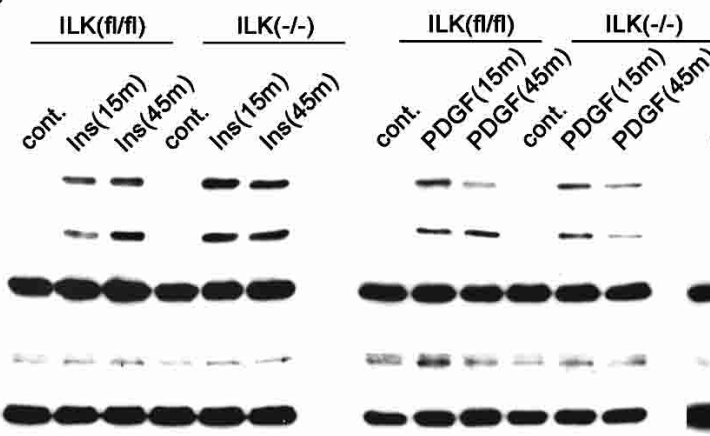

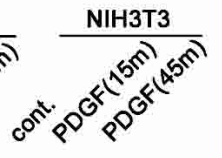

- - PKB/Akt(Thr308)
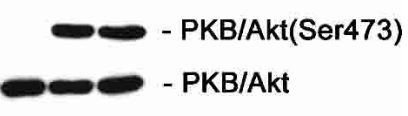

- - GSK3ß(Ser9)

- GSK3 $\beta$

$45 \mathrm{~min}$. Total lysates of the cells were resolved in SDS gel, transferred to a PDVF membrane, and probed with anti-PKB/Akt,

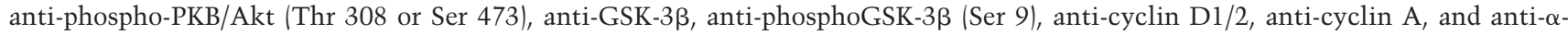
tubulin.

ther a GFP-tagged wild-type ILK cDNA (pCLILKGFP) or GFP-tagged mutant cDNA, in which the glutamic acid 359 (E359) was replaced by a lysine residue (pCLILKGFPE359K). As a control we used a retroviral vector that contains the cDNA for GFP (pCLGFP). The E359K mutation was previously shown to result in a "kinase-dead" ILK mutant and to act in a dominant-negative fashion in several ILK signaling-dependent processes such as cell adhesion and spreading, cell cycle progression, and myogenic differentiation (Hannigan et al. 1996; Delcommenne et al. 1998; Wu et al. 1998; Huang et al. 2000). In addition, it was shown that the E359K mutation may interfere with paxillin binding rather than kinase activity (Nikolopoulos and Turner 2001, 2002).

Infection of ILK-deficient cells with either pCLILKGFP or pCLILKGFP-E359K resulted in robust expression of the transduced cDNA as shown by Western blotting (Fig. $8 \mathrm{~A})$. Furthermore, expression of GFP was observed in $>80 \%$ of the infected cells (data not shown). Cells transduced with pCLGFP failed to spread and did not form FAs and mature stress fibers $4 \mathrm{~h}$ after plating on FN (data not shown). In contrast, cells transduced with pCLILKGFP and pCLILKGFP-E359K were able to induce cell spreading and exhibited FA and stress fiber formation (Fig. 8B,C). In all transduction experiments we observed that $\sim 40 \%$ of the cells expressing either the wildtype ILKGFP or the mutant ILKGFP-E359K spread to the same extent as parental $\mathrm{ILK}^{\mathrm{fl} / \mathrm{fl}}$ cells. This could be caused by the low level of transgene expression in these cells.

Next we determined the proliferation rate of the transduced cells. ILK-deficient cells expressing GFP showed a significantly diminished BrdU incorporation (Fig. 8D) when compared with cells expressing the ILK-GFP or ILKGFP-E359K fusion protein, respectively. Interestingly, cells expressing the mutant ILKGFP-E359K exhibited even higher BrdU incorporation than pCLILKGFPinfected cells.

\section{Discussion}

In the present paper, we report the generation and analysis of ILK-deficient mice and cells. Mice lacking ILK expression failed to polarize epiblast cells and, as a consequence, died during the peri-implantation period. Fibroblasts lacking ILK adhered less to ECM, had defects in cell spreading, showed delayed formation of focal adhesion sites and stress fibers, and a diminished proliferation rate. Surprisingly, treatment of ILK-deficient cells with insulin or PDGF resulted in robust phosphorylation of PKB/Akt and GSK-3 $\beta$ and expression of a "kinase dead" ILK in ILK-deficient fibroblasts rescued the spreading defect, the delayed FA and stress fiber formation, and cell growth reduction.

During the peri-implantation period, the primitive endoderm forms on the surface of the ICM of the blastocyst and deposits a BM. The BM is required for the adjacent ICM cells to polarize and establish the columnar epiblast (primitive ectoderm) and for the remaining ICM cells to undergo apoptosis, resulting in the establishment of the proamniotic cavity (Coucouvanis and Martin 1995). In the absence of ILK the primitive endoderm differentiated and produced a BM. However, there was a severe impediment to subsequent cavitation and polarization of ICM cells to form columnar epiblast cells. This defect is different in $\beta 1$-integrin-deficient mice, which die of an in- 
Sakai et al.
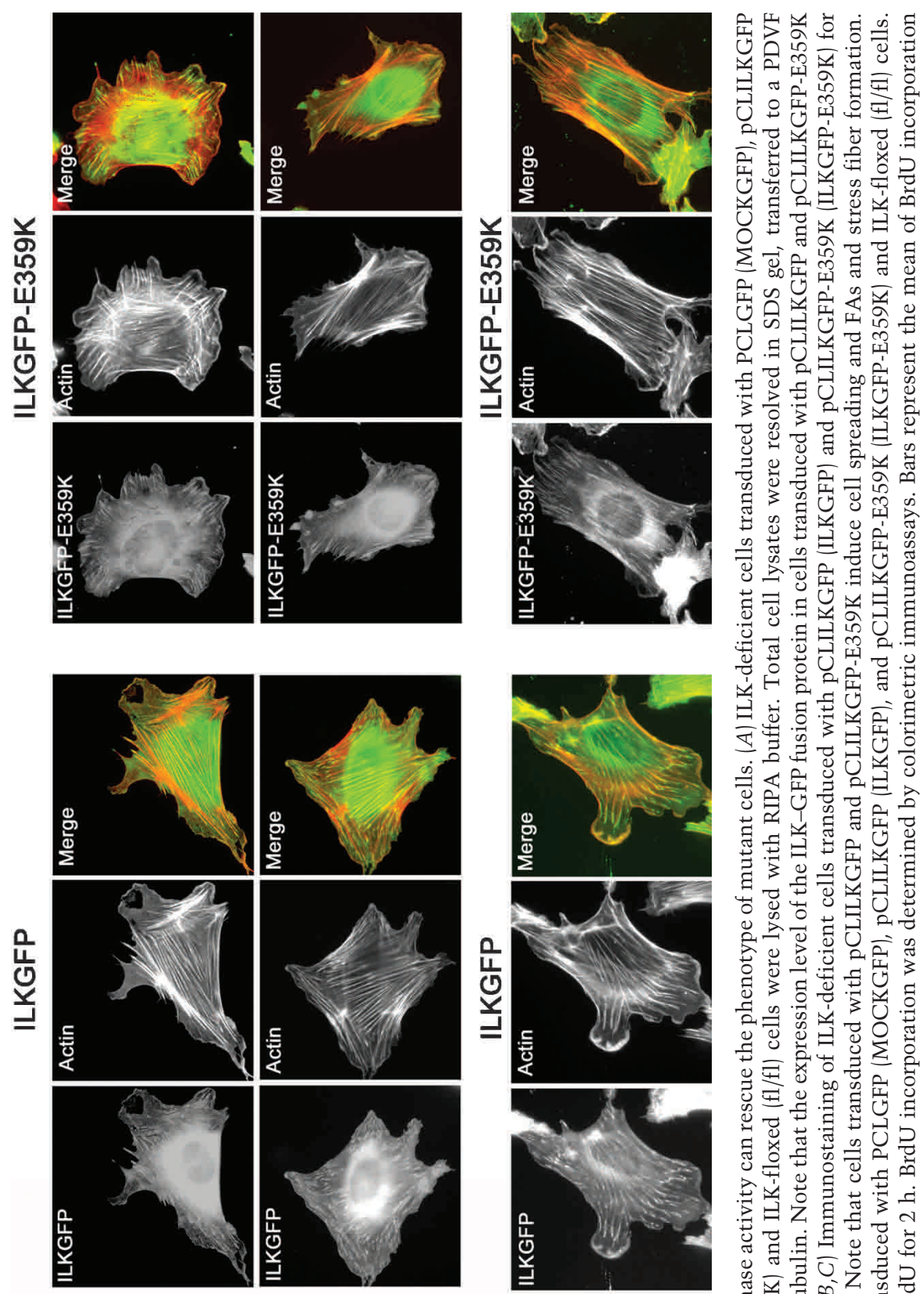

글

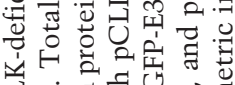

蒠
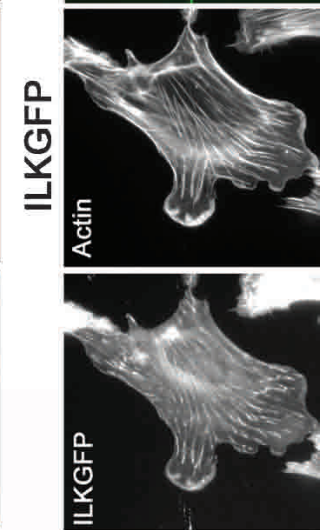

$m$

0

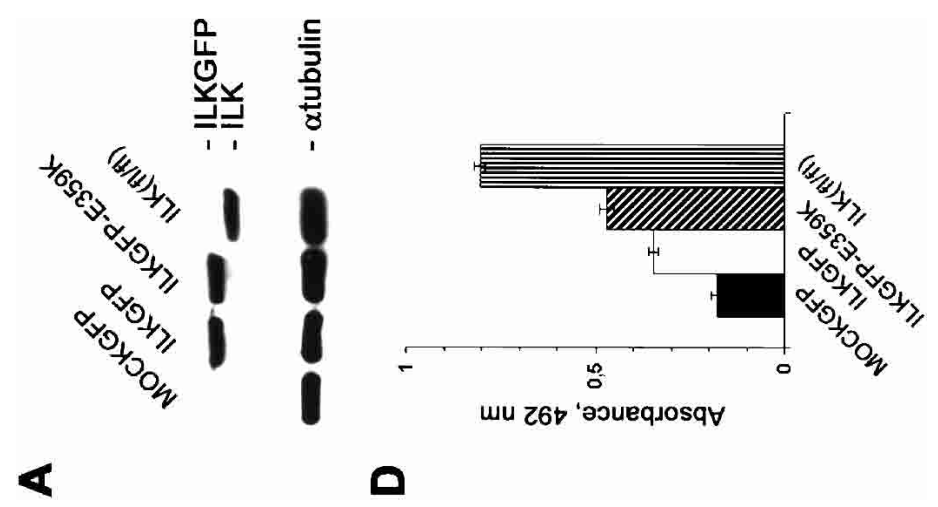

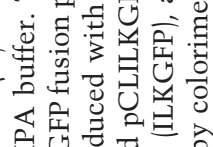

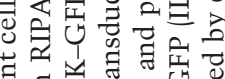

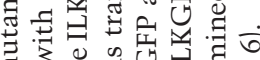

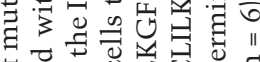

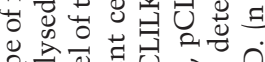
क्षे

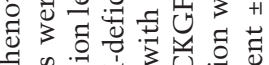

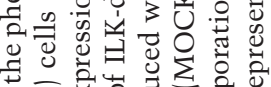

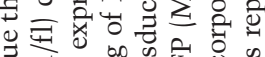

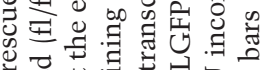

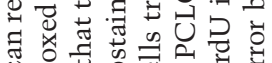

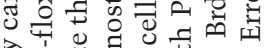

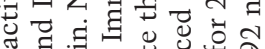

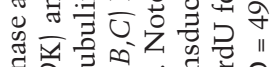

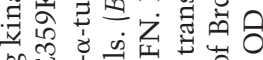
60. 氙焉

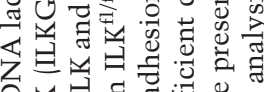

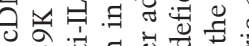
in

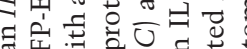

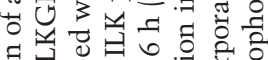

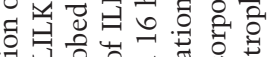

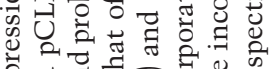

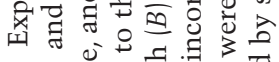

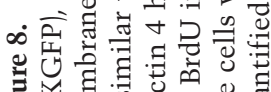

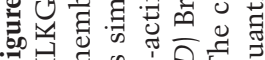


ability of the primitive endoderm to produce laminin $\alpha 1$ and hence a BM (Aumailley et al. 2000; Li et al. 2002). If one overcomes the defect by exogenous addition of laminin, the $\beta 1$-null EBs can lay down a BM, differentiate and polarize an epiblast, and form cavities (Li et al. 2002). These data indicate that there are $\beta 1$-integrin functions independent of ILK, but also ILK functions independent of $\beta 1$-integrin during the peri-implantation period. It is possible that other BM receptors compensate for the loss of $\beta 1$ integrin and, therefore, laminin-1-rescued $\beta 1$-null EBs develop a normal epiblast. Candidate receptors are $\alpha v \beta 3$ integrin and dystroglycan. $\alpha v \beta 3$ integrin, however, does not bind laminin-1, which makes this integrin a rather unlikely candidate. Dystroglycan binds laminin-1 and can be found in FAs (Belkin and Smalheiser 1996). However, nobody has shown so far whether dystroglycan can recruit ILK.

The most striking defect between normal and mutant epiblasts was the different distribution of F-actin. Normal ICM cells adjacent to the endodermal BM displayed a weak and evenly distributed F-actin beneath the entire plasma membrane. During elongation and polarization of the epiblast cells, the F-actin located to the apical side, which faced the cavities. In ILK-null EBs, F-actin accumulated in ICM cells at sites of integrin attachment to the BM prior to polarization. In the few EBs that formed small cavities or slits, some of the F-actin was present in an apical belt but a significant amount remained at the basal side, where integrins attach the epiblast to the BM. These findings indicate that a major function of ILK in epiblast cells is to prevent F-actin accumulation at integrin-adhesion sites to the BM. A similar requirement of ILK to reorganize F-actin was also evident in ILK-deficient fibroblasts, which displayed abnormal aggregates of F-actin beneath the plasma membrane and several other abnormal actin-based processes such as diminished cell spreading and delayed formation of stress fibers and FAs. Other cell types such as endothelial cells and neurons differentiated in EBs but displayed defects that could also be explained by impaired actin dynamics. Neuronal cells lacking ILK were able to make axons, but most of their axonal extensions were shorter. Endothelial cells were present in $I L K$-null EBs. They formed a poor vascular network with only a few branches, suggesting that ILK supports their migration. In spite of the ubiquitous expression of ILK, however, not all cells depend on ILK to modulate their actin filament organization. For instance, epithelial cells such as trophectoderm or endoderm can perfectly reorganize their actin filaments, polarize, and form adherens and tight junctions without ILK. In addition, cardiomyocytes differentiate in ILK-deficient EBs and have apparently normal sarcomeres and twitch in culture. An explanation for the cell-specific requirement could be functional redundancy, which, if it occurs, is most likely accomplished by unrelated proteins because a second, functional ILK gene could be found neither in the mouse nor in the human genome.

Loss-of-function mutations of ILK in Drosophila display a different F-actin defect from what we observed in $I L K$-null epiblast as well as fibroblast cells. Whereas we observed an abnormal F-actin accumulation at sites of integrin adhesion in mutant epiblast and fibroblasts, ILK-deficient flies fail to link actin filaments to integrinadhesion sites in muscle cells, resulting in a detachment rather than an accumulation of F-actin from the cell membrane (Zervas et al. 2001). Although this is a striking difference, there are explanations that could explain the discrepancy. The most likely explanation is that F-actin also accumulates at sites of integrin adhesion in Drosophila muscle cells but detaches from the plasma membrane as soon as they contract. The force generated in contracting muscle is much higher than that generated in cells establishing cell polarity. It will, therefore, be important to test F-actin distribution prior to muscle cell contraction. Furthermore, F-actin localization should be investigated in wing epithelial cells that detach from ECM and give rise to blister formation. An alternative explanation for the discrepancy is that ILK exerts different or opposing functions in different cell types. ILK may be required to attach actin filaments to integrin-adhesion sites in muscle but may also be required to prevent actin accumulation at similar sites in fibroblasts and epithelial cells such as epiblasts. The availability of floxed mice will allow addressing this question in the future by performing skeletal-muscle-specific deletion of the ILK gene in mice.

How can ILK regulate F-actin deposition and/or actin filament insertion to the plasma membranes? Several pathways have been described. First, ILK is able to interact with $\alpha$-parvin and $\beta$-parvin, which can regulate actin either by recruiting the Rac- and Cdc42-specific guanine nucleotide exchange factor $\alpha$ PIX (Rosenberger et al. 2003) or directly binding actin filaments and attaching them to FAs (Tu et al. 2001; Yamaji et al. 2001). The significance of the ILK-parvin interaction was recently demonstrated in a myoblast cell line, in which disruption of the ILK- $\alpha$-parvin complex retarded formation of stress fibers as well as FAs and delayed cell spreading (Tu et al. 2001). Additional evidence comes from loss-offunction studies of PAT- 6 , the $\alpha$-parvin ortholog in $C$. elegans. The mutant worms exhibit muscle detachment caused by defects in actin assembly (Lin and Williams 2000). Second, ILK can bind paxillin, which in turn interacts with binding partners such as $\alpha$-parvin and vinculin, which bind actin filaments and $\alpha$ PIX. In the case of $\alpha$-parvin, overexpression of a mutant protein defective for paxillin binding results in impaired cell adhesion and cell spreading, suggesting that the ability of paxillin to recruit $\alpha$-parvin to the plasma membrane may be a critical step in an $\alpha$-parvin-dependent assembly of actin filaments at these sites of cell adhesion (Nikolopoulos and Turner 2000). Third, ILK can also bind PINCH (Tu et al. 1999|, which may reorganize actin through the Src homology 2 domain- and Src homology 3 domain-containing adaptor protein Nck2 (Nck $\beta$ or Grb4; Tu et al. 1999). Nck2 is present in cell-matrix contact sites (Zhang et al. 2002) and can bind the Wiskott Aldrich Syndrome protein (WASp) and the p21-activated kinase (PAK) that are involved in actin polymerization dependent on as well as independent of Rac and Cdc42. An additional Nck2- 
binding protein is DOCK180 (Tu et al. 2001), which can activate Rac (Kiyokawa et al. 1998). Small GTPases, in particular Cdc42, are well known for their role in establishing epithelial polarity (Erickson and Cerione 2001). We found in preliminary experiments that GFP-tagged PINCH cannot localize to FAs when ILK is absent (F. Stanchi and R. Fässler, unpubl.). Altogether, it will be important in future to test whether downstream functions of PINCH and parvin such as the activities of small Rho GTPases are altered. Remarkably, however, not all epithelial cells are affected by loss of ILK expression. Trophectodermal cells, endodermal cells, or epithelial cells in delayed EBs can differentiate and polarize in the absence of ILK, which suggests a specific requirement of ILK function for only a subset of epithelia.

Deletion of ILK in ES cells as well as fibroblasts severely affected their proliferation. This could have several reasons. On the one hand, loss of ILK expression is associated with severe defects in actin reorganization and cell spreading, which are known to compromise cell cycle progression (Chen et al. 1997). On the other hand, it was shown that ILK modulates the activity of GSK-3 $\beta$ or PKB/Akt (Delcommenne et al. 1998), which can also control cell cycle progression (Lawlor and Alessi 2001; Woodgett 2001). GSK-3 $\beta$ and PKB/Akt are threonine/ serine kinases whose activity is regulated by phosphorylation at specific residues. ILK as well as Wnt signaling can phosphorylate GSK-3 $\beta$ at Ser 9 and thereby inactivate its kinase activity. This leads to accumulation of $\beta$-catenin, which associates with Lef- $1 /$ Tcf, translocates into the nucleus, and activates gene expression. Activation of $\mathrm{PKB} /$ Akt occurs through phosphorylation at Ser 473 by ILK and at Thr 308 by PDK1. Several studies have recently questioned the functional importance of the kinase activity of ILK, which was demonstrated in vitro. It was shown, for example, that ILK with an inactivated kinase domain rescues the lethal phenotype of ILK-deficient flies and worms (Lynch et al. 1999; Hill et al. 2002). Recent biochemical studies with mammalian cells suggested that ILK is rather an adaptor than a kinase and may help to recruit a kinase into a multiprotein complex that phosphorylates PKB/Akt on Ser 473 (Lynch et al. 1999; Hill et al. 2002). Using ILK-deficient cells, we show that ILK is not essential to phosphorylate PKB/Akt or GSK-3 $\beta$ in cultured cells. ILK-deficient fibroblast cells showed a very robust phosphorylation of PKB/Akt on both Thr 308 and Ser 473 after treatment of either insulin or PDGF, which did not differ significantly from control cells. During insulin treatment the phosphorylation levels of Thr 308 and Ser 473 were stable both in control and ILK-null cells. During treatment with PDGF, however, phosphorylation of Ser 473 was down-regulated more quickly in ILK-null cells compared with control cells. These data show that ILK is not required to phosphorylate $\mathrm{PKB} / \mathrm{Akt}$ on Ser 473 but demonstrate a certain role for ILK, at least in some cells and under certain conditions, to maintain the phosphorylation levels over a prolonged period of time. Finally, we were unable to observe a role of ILK for the phosphorylation of GSK-3 $\beta$ on Ser 9. Although the induced phosphorylation was much lower than for PKB/Akt, it was significant in all experiments that have been carried out.

With the isolation of ILK it was also shown that the E359K mutation abolished kinase activity in vitro (Hannigan et al. 1996). Therefore, the ILK-E359K mutant was used as a "kinase dead" ILK in several overexpression studies, which implicated the ILK kinase activity in the regulation of cell adhesion, adhesion-independent growth, FN assembly, phosphorylation of target proteins, and cell differentiation (Wu and Dedhar 2001). Recent reports, however, showed that the E359K mutation may interfere with paxillin binding rather than kinase activity (Nikolopoulos and Turner 2001, 2002). In this study, we demonstrate that the ILK-E359K mutant can revert the defects observed in ILK-deficient cells, indicating that the kinase activity is not essential for ILK function in fibroblasts. Similar results were observed in fly studies in which the E359K and other kinase dead ILK mutants could fully rescue the ILK-null phenotype (Zervas et al. 2001). We observed that $\sim 40 \%$ of transduced cells expressing either the ILK-E359K mutant or the wild-type ILK spread to the same extent as the floxed parental cell line. This could be explained by the fact that we analyzed a mixed population of transduced cells and that the expression levels of mutant or wild-type ILK differ from cell to cell. Rescue of the ILK-deficient phenotype requires a certain level of ILK expression, and cells that express subthreshold concentrations of ILK are unable to fully rescue the mutant phenotype.

\section{Materials and methods}

\section{Generation of ILK-deficient mice}

A 340-bp DNA fragment from the $5^{\prime}$ region of the mouse ILK cDNA was used to screen a PAC library. The ILK ${ }^{\text {lacZ }}$ construct consisted of a 3-kb left arm followed by a lacZ reporter gene and a PKG-driven neo cassette and a 6-kb right arm. The ILK ${ }^{\mathrm{fl}}$ construct consisted of the $3-\mathrm{kb}$ left arm, a single loxP site, an $0.8-\mathrm{kb}$ genomic fragment, a neo-tk cassette flanked by loxP sites, and a 6-kb right arm (for more detailed information contact faessler@biochem.mpg.de.)

To obtain $I L K^{-/-}$ES cells, two ILK ${ }^{\mathrm{fl}}$ ES cell clones that had undergone homologous recombination were transiently transfected with a Cre expression plasmid (a gift from Werner Müller, University of Cologne, Germany) and selected in the presence of FIAU. Surviving ES cell clones were isolated, analyzed by Southern blot, and 2 ES cell clones with one loxP site (constitutive null allele; $+/-\mid$ were re-electroporated again with the $\mathrm{ILK}^{\mathrm{fl}}$ construct. ES cell clones with a recombination event on the wild-type allele were again Cre-treated to obtain ES cell clones with a homozygous deletion of ILK (-/-).

\section{Antibodies}

The following antibodies were used for the analyses: mouse monoclonal antibodies against ILK (clone 3, Transduction lab; clone 65.1.9, Upstate); rabbit antibody against ILK (Upstate); rat $\mathrm{mAb}$ against E-cadherin (Zymed); rat mAb against platelet endothelial cell adhesion molecule (PECAM; Pharmingen); rabbit antibody against neurofilament $M$ (Chemicon); mouse $\mathrm{mAb}$ against myosin (clone MF22); rabbit antibody against laminin$\gamma 1$; mouse mAb against vinculin (sigma); mouse mAb against paxillin (Transduction lab); rabbit antibody against integrin $\beta 1$ 
(Fässler and Meyer 1995); mouse mAb against $\alpha$ smooth muscle cell actin (Sigma); rabbit antibodies against PKB/Akt and phospho-PKB/Akt (Thr 308, Ser 473; Cell Signaling Technology); mouse $\mathrm{mAb}$ against GSK-3 $\beta$ (Transduction lab); rabbit antibody against phospho-GSK-3 $\beta$ (Ser 9; Biosource Int.); mouse mAb against cyclin D1/2 (Upstate); rabbit antibody against cyclin $\mathrm{A}$ (Santa Cruz Biotechnology); and rat $\mathrm{mAb}$ against $\alpha$-tubulin.

Preparation of retroviral vectors and transduction of ILK-deficient cells

The QuickChange site-directed mutagenesis kit (Stratagene) was used to substitute E359 of the mouse ILK cDNA with K. The point mutation was confirmed by sequencing, and both the wild-type and mutant (E359K) ILK cDNAs were fused at the C terminus with EGFP (Clontech). The EGFP-tagged cDNAs were inserted into the pCL vector system (Naviaux et al. 1996). VSVG-pseudotyped retroviral vectors were produced by transient transfection of 293T (human embryonic kidney) cells. The resulting viral supernatant was concentrated as previously described (Pfeifer et al. 2000). In brief, virus was harvested at days 2 and 3 after transfection, filtered $(0.45 \mu \mathrm{m}$ pore size $)$, and concentrated by ultracentrifugation.

ILK-deficient cells, $2 \times 10^{5}$ per $60-\mathrm{mm}$ dish, were infected in $800 \mu \mathrm{L}$ of culture medium (DMEM, $10 \%$ fetal bovine serum) containing concentrated virus. The next day, cells were split into two $60-\mathrm{mm}$ dishes. Twenty-four hours later cells were trypsinized and seeded on FN for 4 and $16 \mathrm{~h}$ for immunostaining, used to determine the proliferation rate (see below), or used for Western blotting.

\section{Culturing of ES cells and embryoid bodies}

Wild-type R1 cells and ILK-null ES cells were cultured as described previously (Li et al. 2002). To evaluate epiblast differentiation, ES cell aggregates were grown in suspension culture for as long as $9 \mathrm{~d}$ as previously described (Li et al. 2002).

To monitor cellular differentiation, ES cells were cultured in hanging drops as described previously (Bloch et al. 1997) and analyzed by immunofluorescence.

\section{Cell cycle and cell proliferation analysis}

For cell cycle analysis, cells were fixed in $70 \%$ ethanol for 45 min on ice, rinsed with PBS, and then stained with $50 \mu \mathrm{g} / \mathrm{mL}$ propidium iodide in PBS containing $20 \mu \mathrm{g} / \mathrm{mL}$ RNase for $30 \mathrm{~min}$ at room temperature. Cell cycle profiles were analyzed by FACS. To detect proliferating cells, cell proliferation ELISA, BrdU (colorimetric) kit (Roche) was used according to the instructions.

\section{FACS analysis}

Flow cytometry was carried out as described previously (Nieswandt et al. 2001).

\section{Adhesion assay}

The attachment of ES cells to extracellular matrix ligands was carried out as previously described (Fässler et al. 1995).

Histological analysis, immunohistochemistry, immunofluorescence, whole mount staining, electron microscopy

For histological analyses, staged embryos were fixed in $4 \%$ fresh paraformaldehyde in PBS overnight $(\mathrm{pH} 7.2)$, dehydrated in a graded alcohol series, and embedded in paraffin (Paraplast X-tra; Sigma Chemical Co.). Sections were cut at $6-8 \mu \mathrm{m}$ and stained with hematoxylin/eosin.

Immunohistochemistry of embryos or tissues and immunofluorescence studies of adhered cells were performed as described previously (Fässler et al. 1995).

For whole mount lacZ analysis, embryos were fixed and stained as described previously (Fässler and Meyer 1995) and finally analyzed under the stereomicroscope (Leica).

For further analysis of EB morphology, EBs were fixed in gluteraldehyde, embedded in Epon, and prepared as thick and thin sections, the former used for light microscopy and the latter for electron microscopy (described in Li et al. 2002).

\section{Cell lysis and immunoblotting}

Cells were grown to $80 \%-90 \%$ confluency, serum-starved for 16 $\mathrm{h}$, and stimulated with $100 \mathrm{ng} / \mathrm{mL}$ PDGF (R\&D systems) or 100 $\mathrm{nM}$ insulin (Sigma) for $15 \mathrm{~min}$ or $45 \mathrm{~min}$. Cell lysis and immunoblotting were performed as described previously (Sakai et al. 1999).

\section{Acknowledgments}

We thank Cord Brakebusch, Nick Brown, and Arnoud Sonnenberg for many dedicated discussions and careful reading of the paper; Oliver Brandau for mouse genome analysis; and Stefan Benkert and Heidi Sebald for expert technical assistance. We gratefully acknowledge the support from NIH (R01 DK36425), DFG (SFB413), Fond der Chemischen Industrie, and the Max Planck Society.

The publication costs of this article were defrayed in part by payment of page charges. This article must therefore be hereby marked "advertisement" in accordance with 18 USC section 1734 solely to indicate this fact.

\section{References}

Aumailley, M., Pesch, M., Tunggal, L., Gaill, F., and Fässler, R. 2000. Altered synthesis of laminin 1 and absence of basement membrane component deposition in $\beta 1$ integrin-deficient embryoid bodies. J. Cell Sci. 113: 259-268.

Belkin, A.M. and Smalheiser, N.R. 1996. Localization of cranin (dystroglycan) at sites of cell-matrix and cell-cell contact: Recruitment to focal adhesions is dependent upon extracellular ligands. Cell Adhes. Commun. 4: 281-296.

Bloch, W., Forsberg, E., Lentini, S., Brakebusch, C., Martin, K., Krell, H.W., Weidle, U.H., Addicks, K., and Fässler, R. 1997. $\beta 1$ integrin is essential for teratoma growth and angiogenesis. J. Cell Biol. 139: 265-277.

Brakebusch, C., Bouvard, D., Stanchi, F., Sakai, T., and Fässler, R. 2002. Integrins in invasive growth. J. Clin. Invest. 109: 999-1006.

Braun, A., Bordoy, R., Stanchi, F., Moser, M., Kostka, G., Ehler, E., and Fässler, R. 2003. PINCH2 is a new five LIM domain protein, homologous to PINCH and localized to focal adhesions. Exp. Cell Res. (In press).

Chen, C.S., Mrksich, M., Huang, S., Whitesides, G.M., and Ingber, D.E. 1997. Geometric control of cell life and death. Science 276: 1425-1428.

Coucouvanis, E. and Martin, G.R. 1995. Signals for death and survival: A two-step mechanism for cavitation in the vertebrate embryo. Cell 83: 279-287.

Delcommenne, M., Tan, C., Gray, V., Rue, L., Woodgett, J., and Dedhar, S. 1998. Phosphoinositide-3-OH kinase-dependent regulation of glycogen synthase kinase 3 and protein kinase 
B/AKT by the integrin-linked kinase. Proc. Natl. Acad. Sci. 95: 11211-11216.

Erickson, J.W. and Cerlone, R.A. 2001. Multiple roles of Cdc42 in cell regulation. Curr. Opin. Cell Biol. 13: 153-157.

Fässler, R. and Meyer, M. 1995. Consequences of lack of $\beta 1$ integrin gene expression in mice. Genes \& Dev. 9: 18961908.

Fässler, R., Pfaff, M., Murphy, J., Noegel, A., Johansson, S., Timpl, R., and Albrecht, R. 1995. Lack of $\beta 1$ integrin gene in embryonic stem cells affects morphology, adhesion and migration but not integration into the inner cell mass of blastocysts. J. Cell Biol. 128: 979-988.

Giancotti, F.G. and Ruoslahti, E. 1999. Integrin signaling. Science 285: 1028-1032.

Hannigan, G.E., Leung-Hagesteijn, C., Fitz-Gibbon, L., Coppolino, M.G., Radeva, G., Filmus, J., Bell, J.C., and Dedhar, S. 1996. Regulation of cell adhesion and anchorage-dependent growth by a new $\beta 1$-integrin-linked protein kinase. Nature 379: 91-96.

Hill, M., Feng, J., and Hemmings, B. 2002. Identification of a plasma membrane Raft-associated PKB Ser473 kinase activity that is distinct from ILK and PDK1. Curr. Biol. 12: 12511255.

Huang, Y., Li, J., Zhang, Y., and Wu, C. 2000. The roles of integrin-linked kinase in the regulation of myogenic differentiation. J. Cell Biol. 150: 861-871.

Hynes, R.O. 2002. Integrins: Bidirectional, allosteric signaling machines. Cell 110: 673-687.

Kiyokawa, E., Hashimoto, Y., Kobayashi, S., Sugimura, H., Kurata, T., and Matsuda, M. 1998. Activation of Rac1 by a Crk SH3-binding protein, DOCK180. Genes \& Dev. 12: 33313336.

Lawlor, M.A. and Alessi, D.R. 2001. PKB/Akt: A key mediator of cell proliferation, survival and insulin responses? J. Cell Sci. 114: 2903-2910.

Li, S., Carbonetto, S., Fässler, R., Smyth, N., Edgar, D., and Yurchenco, P.D. 2002. Matrix assembly, regulation and survival functions of laminin and its receptors in embryonic stem cell differentiation. J. Cell. Biol. 157: 1279-1290.

Lin, X. and Williams, B.S. 2000. 40th American Society for Cell Biology Meeting, Abstr. 2666.

Lynch, D.K., Ellis, C.A., Edwards, P.A., and Hiles, I.D. 1999. Integrin-linked kinase regulates phosphorylation of serine 473 of protein kinase B by an indirect mechanism. Oncogene 18: 8024-8032.

Mackinnon, A.C., Qadota, H., Norman, K.R., Moerman, D.G., and Williams, B.D. 2002. C. elegans PAT-4/ILK functions as an adaptor protein within integrin adhesion complexes. Curr. Biol. 12: 787-797.

Naviaux, R.K., Costanzim, E., Haasm, M., and Verma, I.M. 1996. The pCL vector system: Rapid production of helperfree, high-titer, recombinant retroviruses. J. Virol. 70: 57015705.

Nieswandt, B., Brakebusch, C., Bergmeier, W., Schulte, V., Bouvard, D., Mokhtari-Nejad, R., Lindhout, T., Heemskerk, J.W.M., Zirngibl, H., and Fässler, R. 2001. Glycoprotein VI but not $\alpha 2 \beta 1$ integrin is essential for platelet interaction with collagen. EMBO T. 20: 2120-2130.

Nikolopoulos, S.N. and Turner, C.E. 2000. Actopaxin, a new focal adhesion protein that binds paxillin LD motifs and actin and regulates cell adhesion. J. Cell Biol. 151: 1435-1448.

—. 2001. Integrin-linked kinase (ILK) binding to paxillin LD1 motif regulates ILK localization to focal adhesions. $J$. Biol. Chem. 276: 23499-23505.

2002. Molecular dissection of actopaxin-integrin-linked kinase-paxillin interactions and their role in subcellular localization. J. Biol. Chem. 277: 1568-1575.

Novak, A., Hsu, S.C., Leung-Hagesteijn, C., Radeva, G., Papkoff, J., Montesano, R., Roskelley, C., Grosschedl, R., and Dedhar, S. 1998. Cell adhesion and the integrin-linked kinase regulate the LEF-1 and $\beta$-catenin signaling pathways. Proc. Natl. Acad. Sci. 95: 4374-4379.

Olski, T.M., Noegel, A.A., and Korenbaum, E. 2001. Parvin, a 42 $\mathrm{kDa}$ focal adhesion protein, related to the $\alpha$-actinin superfamily. J. Cell Sci. 114: 525-538.

Persad, S., Attwell, S., Gray, V., Mawji, N., Deng, J.T., Leung, D., Yan, J., Sanghera, J., Walsh, M.P., and Dedhar, S. 2001. Regulation of protein kinase B/Akt-serine 473 phosphorylation by integrin-linked kinase: Critical roles for kinase activity and amino acids arginine 211 and serine 343. J. Biol. Chem. 276: 27462-27469.

Pfeifer, A., Kessler, T., Silletti, S., Cheresh, D.A., and Verma, I.M. 2000. Suppression of angiogenesis by lentiviral delivery of PEX, a noncatalytic fragment of matrix metalloproteinase 2. Proc. Nat1. Acad. Sci. 97: 12227-12232.

Rosenberger, G., Jantke, I., Galand, A., and Kutsche, K. 2003. Interaction of $\alpha$ PIX (ARHGEF6) with $\beta$-parvin (PARVB) suggests an involvement of $\alpha$ PIX in integrin-mediated signaling. Hum. Mol. Gen. 12: 155-167.

Sakai, T., de la Pena, J.M., and Mosher, D.F. 1999. Synergism among lysophosphatidic acid, $\beta 1$-integrins, and EGF or PDGF in mediation of cell migration. J. Biol. Chem. 274: 15480-15486.

Tu, Y., Li, F., and Wu, C. 1998. Nck-2, a novel Src homology2/ 3 -containing adaptor protein that interacts with the LIMonly protein PINCH and components of growth factor receptor kinase-signaling pathways. Mol. Cell. Biol. 9: 3367-3382.

Tu, Y., Li, F., Goicoechea, S., and Wu, C. 1999. The LIM-only protein $\mathrm{PINCH}$ directly interacts with integrin-linked kinase and is recruited to integrin-rich sites in spreading cells. Mol. Cell. Biol. 19: 2425-2434.

Tu, Y., Huang, Y., Zhang, Y., Hua, Y., and Wu, C. 2001. A new focal adhesion protein that interacts with integrin-linked kinase and regulates cell adhesion and spreading. I. Cell Biol. 153: $585-598$.

Woodgett, J.R. 2001. Judging a protein by more than its name: GSK-3. SCiSTKE 2001 (100): RE12.

Wu, C. and Dedhar, S. 2001. Integrin-linked kinase (ILK) and its interactors: A new paradigm for the coupling of extracellular matrix to actin cytoskeleton and signaling complexes. J. Cell Biol. 155: 505-510.

Wu, C., Keightley, S.Y., Leung-Hagesteijn, C., Radeva, G., Coppolino, M., Goicoechea, S., McDonald, J.A., and Dedhar, S. 1998. Integrin-linked protein kinase regulates fibronectin matrix assembly, E-cadherin expression, and tumorigenicity. J. Biol. Chem. 273: 528-536.

Yamaji, S., Suzuki, A., Sugiyama, Y., Koide, Y., Yoshida, M., Kanamori, H., Mohri, H., Ohno, S., and Ishigatsubo, Y. 2001. A novel integrin-linked kinase-binding protein, Affixin, is involved in the early stage of cell-substrate interaction. $J$. Cell Biol. 153: 1251-1264.

Zervas, C.G., Gregory, S.L., and Brown, N.H. 2001. Drosophila integrin-linked kinase is required at sites of integrin adhesion to link the cytoskeleton to the plasma membrane. $J$. Cell Biol. 152: 1007-1018.

Zhang, Y., Chen, K., Guo, L., and Wu, C. 2002. Characterization of PINCH-2, a new focal adhesion protein that regulates the PINCH-1-ILK Interaction, cell spreading, and migration. J. Biol. Chem. 277: 38328-38338. 


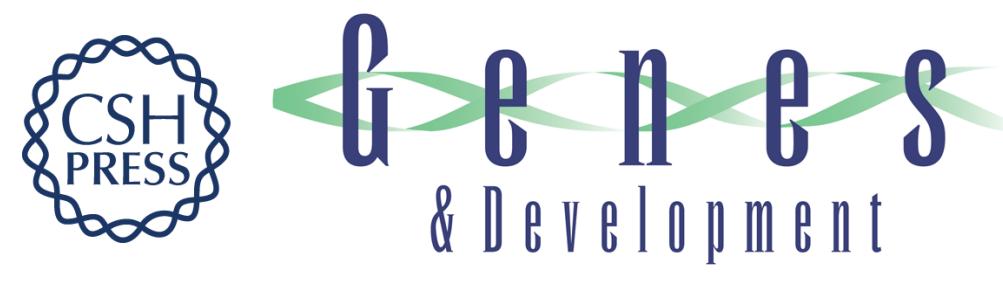

\section{Integrin-linked kinase (ILK) is required for polarizing the epiblast, cell adhesion, and controlling actin accumulation}

Takao Sakai, Shaohua Li, Denitsa Docheva, et al.

Genes Dev. 2003, 17:

Access the most recent version at doi:10.1101/gad.255603

References This article cites 38 articles, 27 of which can be accessed free at: http://genesdev.cshlp.org/content/17/7/926.full.htmI\#ref-list-1

License

Email Alerting

Receive free email alerts when new articles cite this article - sign up in the box at the top Service right corner of the article or click here.

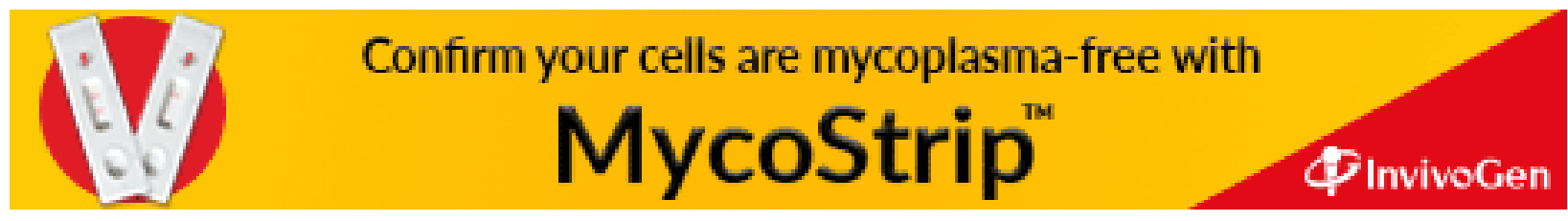

